\title{
Inactivation of specific $\beta$ cell transcription factors in type 2 diabetes
}

\author{
Shuangli Guo, ${ }^{1}$ Chunhua Dai, ${ }^{2}$ Min Guo, ${ }^{1}$ Brandon Taylor, ${ }^{3}$ Jamie S. Harmon, ${ }^{4}$ Maike Sander, ${ }^{3}$ \\ R. Paul Robertson, ${ }^{4}$ Alvin C. Powers, ${ }^{1,2,5}$ and Roland Stein ${ }^{1}$
}

\begin{abstract}
1Department of Molecular Physiology and Biophysics, Vanderbilt University Medical Center, Nashville, Tennessee, USA. Division of Diabetes, Endocrinology, and Metabolism, Department of Medicine, Vanderbilt University, Nashville, Tennessee, USA. ${ }^{3}$ Departments of Pediatrics and Cellular and Molecular Medicine, Pediatric Diabetes Research Center, University of California at San Diego, La Jolla, California, USA. University of Washington, Division of Metabolism, Endocrinology, and Nutrition, Departments of Medicine and Pharmacology, and the Pacific Northwest Diabetes Research Institute, Seattle,
\end{abstract}

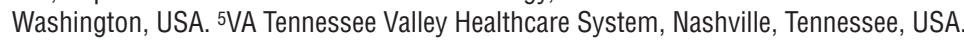

\begin{abstract}
Type 2 diabetes (T2DM) commonly arises from islet $\beta$ cell failure and insulin resistance. Here, we examined the sensitivity of key islet-enriched transcription factors to oxidative stress, a condition associated with $\beta$ cell dysfunction in both type 1 diabetes (T1DM) and T2DM. Hydrogen peroxide treatment of $\beta$ cell lines induced cytoplasmic translocation of MAFA and NKX6.1. In parallel, the ability of nuclear PDX1 to bind endogenous target gene promoters was also dramatically reduced, whereas the activity of other key $\beta$ cell transcriptional regulators was unaffected. MAFA levels were reduced, followed by a reduction in NKX6.1 upon development of hyperglycemia in $d b / d b$ mice, a T2DM model. Transgenic expression of the glutathione peroxidase-1 antioxidant enzyme (GPX1) in $d b / d b$ islet $\beta$ cells restored nuclear MAFA, nuclear NKX6.1, and $\beta$ cell function in vivo. Notably, the selective decrease in MAFA, NKX6.1, and PDX1 expression was found in human T2DM islets. MAFB, a MAFA-related transcription factor expressed in human $\beta$ cells, was also severely compromised. We propose that MAFA, MAFB, NKX6.1, and PDX1 activity provides a gauge of islet $\beta$ cell function, with loss of MAFA (and/or MAFB) representing an early indicator of $\beta$ cell inactivity and the subsequent deficit of more impactful NKX6.1 (and/or PDX1) resulting in overt dysfunction associated with T2DM.
\end{abstract}

\section{Introduction}

Oxidative stress appears to contribute to pancreatic islet $\beta$ cell dysfunction in both type 1 (T1DM) and type 2 (T2DM) diabetes (1-6). As a consequence, understanding how oxidative stress impacts $\beta$ cells is clearly of therapeutic relevance. Compelling evidence indicates that the accumulation of ROS, such as hydroxyl radical and hydrogen peroxide $\left(\mathrm{H}_{2} \mathrm{O}_{2}\right)$ generated by increased glucose and/or lipid metabolism, causes cell inactivation and death (7). For example, the levels of oxidative stress markers are significantly higher in human T2DM islets (e.g., 3 -nitrotyrosine and 8-hydroxy-2'-deoxyguanosine) (8, 9). Notably, islet $\beta$ cells have unusually low antioxidant enzyme levels (e.g., glutathione peroxidase-1 [GPX1] and catalase), thus exposing their proteins, lipids, and/or DNA to oxidative modifications $(10,11)$. Importantly, antioxidant treatment can prevent the onset of diabetes in animal models of T1DM $(6,12)$ as well as improve $\beta$ cell function in T2DM animal models $(3-6,12,13)$ and human T2DM islets $(8,9,14)$.

Maturity-onset diabetes of the young (MODY) typically results from mutations in islet-enriched transcription factors, with 6 of 9 MODY genes encoding transcription factors that are required in $\beta$ cell development and/or function $(15,16)$. Furthermore, mutations in other distinct islet transcription factors decrease $\beta$ cell function in vivo (e.g., MAFA, refs. 17, 18; NGN3, ref. 19; and PAX6, refs. 20,21). Collectively, these observations indicate that islet $\beta$ cell transcription factors could be primary targets of oxidative stress, with reduced (or induced) expression of their target genes resulting in cell dysfunction.

Conflict of interest: The authors have declared that no conflict of interest exists. Citation for this article: J Clin Invest. 2013;123(8):3305-3316. doi:10.1172/JCI65390.
Experiments with $\beta$ cell lines have demonstrated that 2 transcription factors, MAFA and PDX1, are inactivated under the oxidative stress conditions imposed by supraphysiological glucose levels (22). For example, the reduction in insulin-driven reporter activity and insulin mRNA levels coincided with a specific reduction in PDX1 and MAFA gel-shift binding activity, although the change in MAFA occurred earlier than in PDX1 and correlated more closely with the loss in insulin expression (23). Notably, mice only lacking MAFA in the pancreas (i.e., termed Mafa ${ }^{\Delta P a n c}$ ) (18) are glucose intolerant, but have normal fasting glucose levels, whereas loss of PDX1 from islet $\beta$ cells causes overt hyperglycemia (24-27). These data suggest that $\beta$ cell inactivity results from the stepwise loss of MAFA and then PDX1 under glucotoxic conditions $(22,23,28)$. Interestingly, the $\mathrm{N}$-acetyl-L-cysteine antioxidant improved both MAFA (referred to as RIPE3b1 activator) and PDX1 gel-shift-binding ability as well as $\beta$ cell function in HIT-T15 $\beta$ cells and in the ZDF T2DM rat model $(3,4)$. Moreover, transgenic $\beta$ cell-specific Gpx1 expression profoundly increased $\beta$ cell function in the T2DM $d b / d b$ mouse model, coinciding with the recovery of nuclear MAFA (5). The insulin secretion defects in human T2DM islets were also improved in vitro upon treatment with $\operatorname{ROS}$ scavengers $(8,9,14)$.

In this study, islet-enriched transcription factor levels and activity in $\beta$ cell lines were first screened for sensitivity to $\mathrm{H}_{2} \mathrm{O}_{2}$, an effector of oxidative stress. Our results demonstrated that MAFA, MAFB, PDX1, and NKX6.1 were selectively inactivated. We further observed that MAFA and NKX6.1, the latter being essential for islet $\beta$ cell development and function (29-31), were sequentially and selectively lost upon induction of hyperglycemia in $d b / d b$ mice. Nuclear NKX6.1 and MAFA were restored by transgenic Gpx1 antioxidant enzyme production in $d b / d b$ islet $\beta$ cells. Importantly, MAFA, MAFB, PDX1, and NKX6.1 levels were also severely 
A

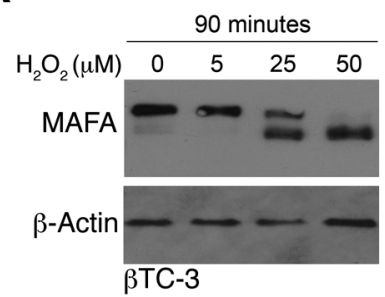

D

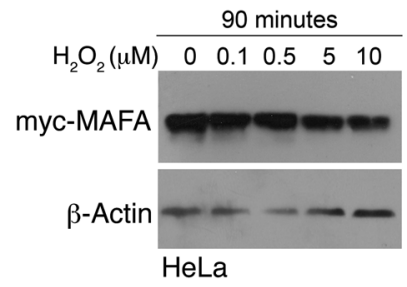

B

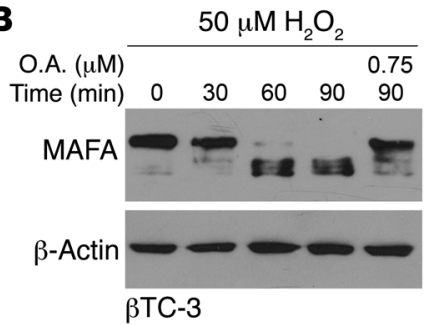

E

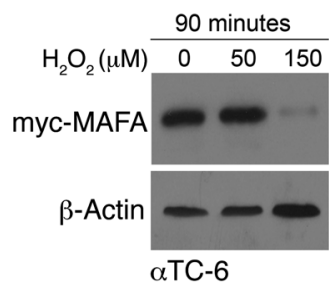

$\mathbf{C}$

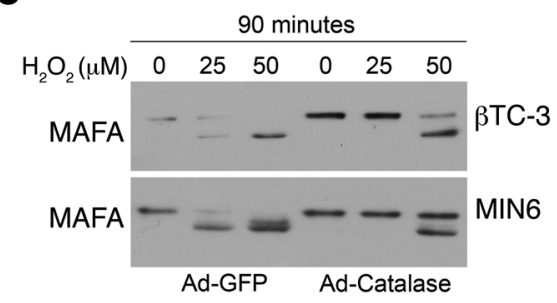

Sucrose gradient fraction no.

F

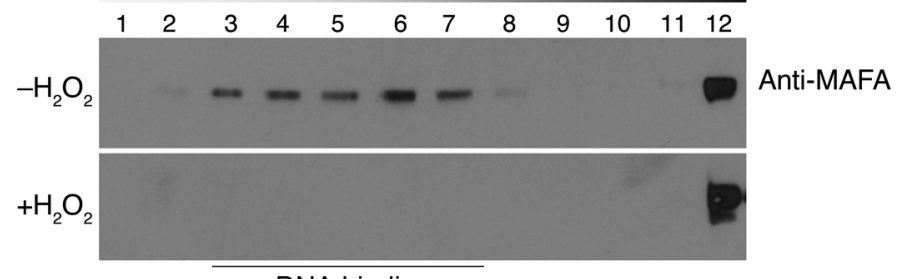

DNA binding

Figure 1

$\mathrm{H}_{2} \mathrm{O}_{2}$ treatment induces MAFA dephosphorylation in $\beta$ TC-3 cells but not in HeLa or $\alpha$ TC- 6 cells. (A) $\beta$ TC-3 cells treated with $\mathrm{H}_{2} \mathrm{O}_{2}$. (B) $\beta$ TC-3 cells incubated with $0.75 \mu \mathrm{M}$ okadiac acid (O.A.) for 30 minutes before $\mathrm{H}_{2} \mathrm{O}_{2}$ addition. (C) Adenovirus-driven catalase decreases the effect of $\mathrm{H}_{2} \mathrm{O}_{2}$. (D and E) Transfected myc-MAFA is not dephosphorylated after $\mathrm{H}_{2} \mathrm{O}_{2}$ treatment in HeLa cells or $\alpha$ TC- 6 cells. (F) $\beta T C-3$ cells were treated with (+) or without (-) $50 \mu \mathrm{M} \mathrm{H}_{2} \mathrm{O}_{2}$ for 90 minutes, and the whole-cell extract was separated by sucrose gradient ultracentrifugation (35). The MAFA DNA-binding species (fractions 3-7) was not detected after $\mathrm{H}_{2} \mathrm{O}_{2}$-induced dephosphorylation (data not shown and ref. 35). (A-F) MAFA protein was analyzed by immunoblotting.

compromised in human T2DM islets. Overall, our results strongly suggest that inactivation of a specific subset of islet-enriched transcriptional regulators contributes to $\beta$ cell dysfunction in T2DM. We propose the possibility that disease progression involves the early loss of MAFA (and/or MAFB), with debilitating $\beta$ cell function resulting from increased production of stress factors and subsequent loss of PDX1 and/or NKX6.1.

\section{Results}

MAFA is translocated to the cytoplasm and dephosphorylated under oxidative stress conditions. MAFA is heavily phosphorylated in vivo, a posttranslational modification regulating dimerization and DNA binding, transactivation capacity, and stability (32-35). To determine whether oxidative stress affects MAFA phosphorylation, $\beta$ TC-3 cells were briefly treated with $\mathrm{H}_{2} \mathrm{O}_{2}$ and whole-cell extracts were probed for MAFA by immunoblotting. The SDS-PAGE mobility of MAFA was substantially faster after exposure to $\mathrm{H}_{2} \mathrm{O}_{2}$ (Figure $1 \mathrm{~A})$, migrating in a manner observed after serine/threonine protein phosphatase treatment (35). Pretreatment of $\beta$ TC- 3 cells with okadiac acid, an inhibitor of endogenous protein phosphatase (PP) 1 and $2 \mathrm{~A}(36)$, prevented this change in mobility (Figure 1B). Infecting $\beta$ TC- 3 or MIN $6 \beta$ cells with adenovirus-driven catalase, an $\mathrm{H}_{2} \mathrm{O}_{2}$ scavenger, attenuated the impact of $\mathrm{H}_{2} \mathrm{O}_{2}$ on MAFA dephosphorylation (Figure 1C). In addition, the sucrose gradient sedimentation properties of MAFA were impacted by $\mathrm{H}_{2} \mathrm{O}_{2}$ treatment, with localization now exclusively in the fraction containing high molecular weight proteins and not in the approximately $92 \mathrm{kD}$ MAFA species capable of DNA binding (Figure 1F) (35).

MAFA is found in the $d b / d b \beta$ cell cytoplasm under hyperglycemic conditions (5). In addition, PDX1 shuttling between the nuclear periphery and nucleoplasm is phosphorylation dependent and regulated by external stimuli (i.e., glucose and insulin) (37).
Cytoplasmic and nuclear fractions from $\mathrm{H}_{2} \mathrm{O}_{2}$-treated $\beta$ TC- 3 cells were collected and probed for MAFA by immunoblotting to determine whether $\mathrm{H}_{2} \mathrm{O}_{2}$ treatment affected subcellular distribution. MAFA was found in the cytoplasm within 30 minutes after $\mathrm{H}_{2} \mathrm{O}_{2}$ treatment, while little remained in the nucleus after 90 minutes (Figure 2A). Cytoplasmic accumulation was dependent on exposure time and dosage (Figure 2, A and B). In addition, cytoplasmic MAFA was clearly detectable by immunofluorescence staining in treated $\beta$ TC- 3 cells (Figure $2 \mathrm{C}$ ).

The susceptibility of MAFA to oxidative inactivation was compared with MAFB, a closely related islet-enriched protein $(18,38$, 39). MAFB was equally responsive to $\mathrm{H}_{2} \mathrm{O}_{2}$ in $\beta$ TC-3 cells (Figure $2 \mathrm{E}$ ), with C-terminal sequences spanning the conserved MAFA and MAFB DNA-binding/dimerization domain sufficiently to mediate nuclear-to-cytoplasmic translocation (see myc-MAFA [210-323] and myc-MAFB [210-323] in Supplemental Figure 1A). Notably, translocation was unaffected by pretreatment with okadiac acid, a phosphatase inhibitor that prevents MAFA dephosphorylation in vivo (Supplemental Figure 1B), or by C-terminal phosphorylation site mutants (Supplemental Figure 1, A and B). These results demonstrate that MAFA dephosphorylation is not necessary for cytoplasmic translocation, with dephosphorylation likely catalyzed by PP1 and/or PP2A in the cytoplasm (Figure 2A).

Oxidation-mediated inactivation of MAFA results from covalent dimer formation by C-terminal cysteines. MAFA was only dephosphorylated (Figure 1, D and E) and translocated to the cytoplasm (Figure 2, F and $\mathrm{G}$ ) after $\mathrm{H}_{2} \mathrm{O}_{2}$ treatment of $\beta$ cell lines, and not non- $\beta$ cell lines (i.e., HeLa or $\alpha$ TC-6). However, the non- $\beta$ cell lines were responsive to $\mathrm{H}_{2} \mathrm{O}_{2}$ treatment (40), as noted, for example, by the translocation of the FOXO1 transcription factor from the cytoplasm to the nucleus in $\alpha$ TC- 6 cells (Figure 2D), which occurs under a variety of different stress conditions $(41,42)$. The ability of exogenously 
A

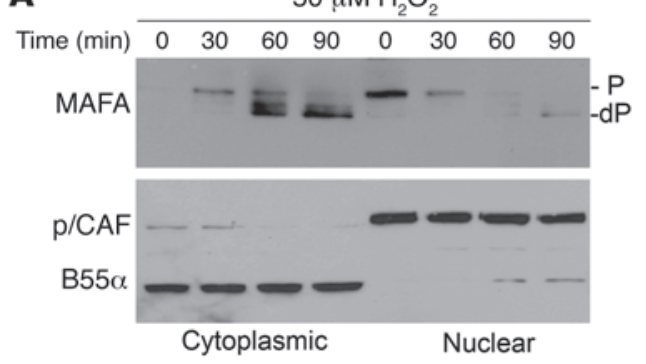

B

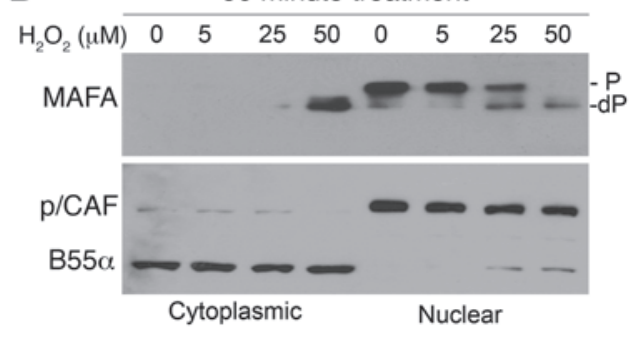

Figure 2

MAFA is translocated to the cytoplasm after $\mathrm{H}_{2} \mathrm{O}_{2}$ treatment. (A and $\mathbf{B}$ ) Immunoblotting to determine MAFA levels in the cytoplasmic and nuclear fractions of $\beta T C-3$ cells. Subcellular marker controls: nuclear, p/CAF coactivator; cytoplasm, $\mathrm{B} 55 \alpha$ regulatory subunit of PP2A. The immunosignal shows (C) MAFA, (D) FOXO1, (E-G) myc-MAFA, or (E) mycMAFB levels in cells treated with $\mathrm{H}_{2} \mathrm{O}_{2}$ for 90 minutes. Yopro (blue) staining labels the nuclei. Notably, myc-MAFA is not cytoplasmic in non $-\beta$ cell lines ( $F$ and $\mathbf{G}$ ) after $\mathrm{H}_{2} \mathrm{O}_{2}$ treatment, although endogenous FOXO1 (D) is relocalized to the nucleus. P, phosphorylated; $\mathrm{dP}$, dephosphorylated.
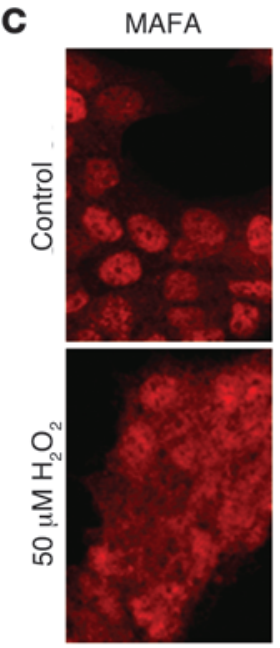

$\beta$ TC-3

E

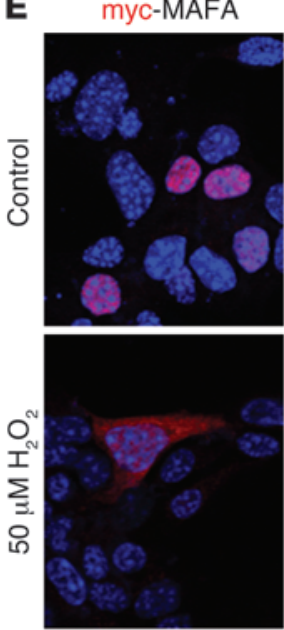

$\beta$ TC-3

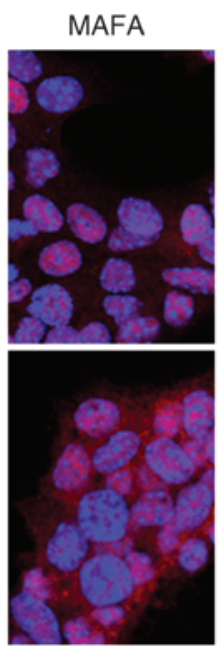

$\beta$ TC-3

myc-MAFB
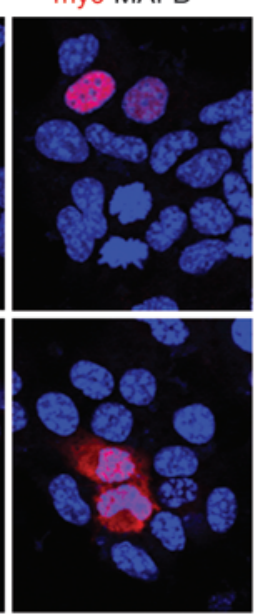

$\beta \mathrm{TC}-3$

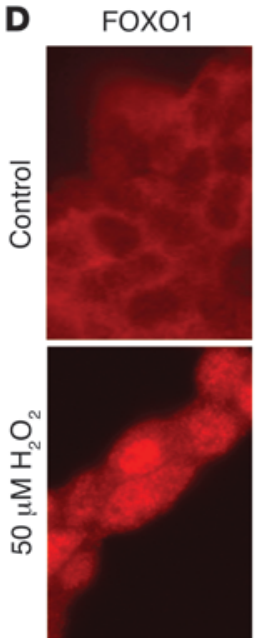

$\beta \mathrm{TC}-3$
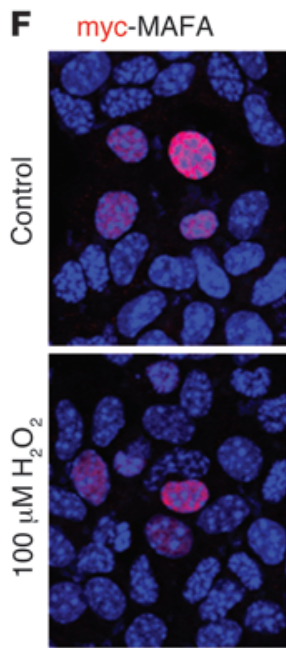

$\alpha \mathrm{TC}-6$

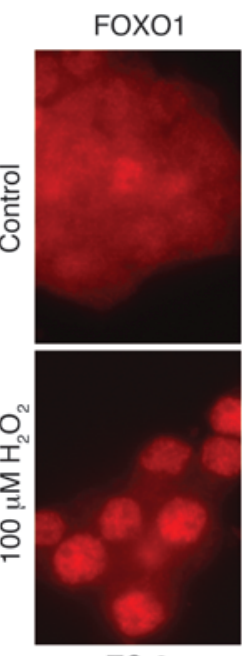

$\alpha \mathrm{TC}-6$

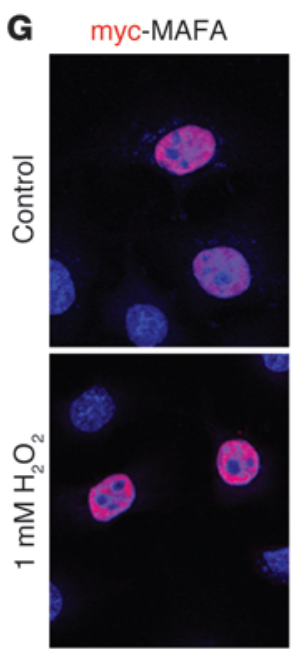

HeLa expressed catalase to attenuate $\mathrm{H}_{2} \mathrm{O}_{2}$ effects on MAFA in $\beta$ TC-3 and MIN6 cells suggests a relatively low antioxidant enzyme level of $\beta$ cells (Figure 1C). As a further test, we analyzed whether MAFA and/or PDX1 DNA-binding activity in $\beta$ TC-3 nuclear extracts was dependent on the DTT-reducing agent. Notably, only MAFA activity required the presence of DTT (Figure 3A). However, MAFA activity was also sensitive to these conditions in HeLa-transfected extracts, with inactivation coinciding with covalent dimer formation (MAFA) ${ }_{2}$ (Figure 3B). Analysis of cysteine mutations throughout MAFA, an amino acid particularly responsive to oxidative conditions, demonstrated a distinct sensitivity of C277 and C293 to $\mathrm{H}_{2} \mathrm{O}_{2}$ treatment (Figure $3 \mathrm{C}$ ). Thus, (MAFA) $)_{2}$ was not produced, and the DNA-binding activity of MAFA was unaffected by the C277/293A mutation in HeLa-transfected cell extracts, but was affected by the C42/59/69S mutation. Moreover, these same conserved basic leucine-zipper dimerization region cysteines in MAFB were solely responsive to oxidative stress (data not shown). Notably, only the migration and native MAFA levels were compromised in $\beta$ TC-3 nuclear extracts prepared in the absence of DTT [Figure 3D, note the (MAFA) 2 production] compared with other islet-enriched 
A
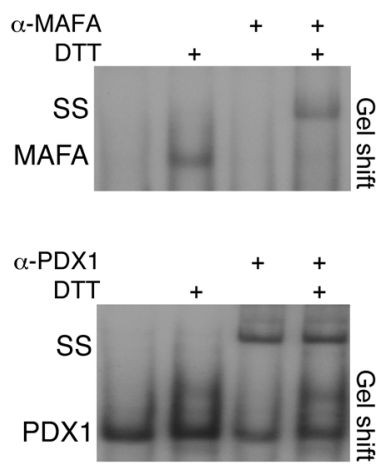

B

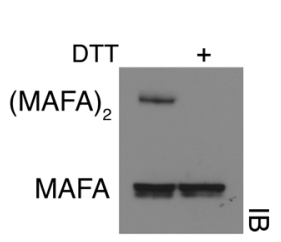

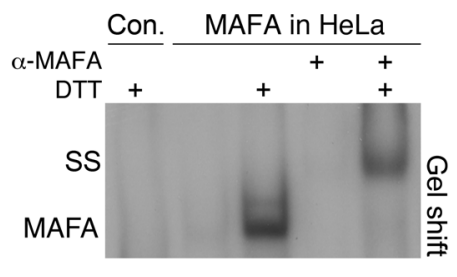

C

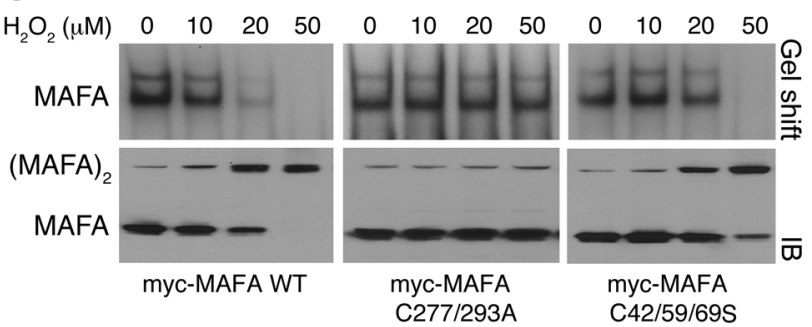

D

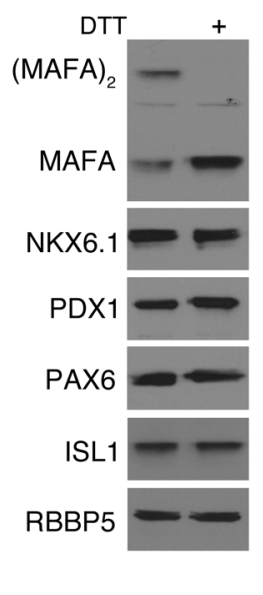

\section{Figure 3}

MAFA forms a covalent dimer species unable to bind DNA under oxidative stress conditions. (A) MAFA and PDX1 DNA-binding activity in $\beta$ TC-3 nuclear extract reactions conducted in the presence $(+)$ and absence of 20 mM DTT. (B) Transfected myc-MAFA containing HeLa nuclear extracts prepared in the absence of DTT was analyzed in gel-shift (right panel: [+] 20 mM DTT) and immunoblotting assays (left panel: [+] 300 mM DTT). (C) The HeLa-produced myc-MAFA C277/C293A mutant does not lose gel-shift activity or form (MAFA) ${ }_{2}$ after $\mathrm{H}_{2} \mathrm{O}_{2}$ treatment, in contrast to WT or mutant C42/59/69S myc-MAFA. (D) Immunoblotting shows that only native MAFA (i.e., $46 \mathrm{kD}$ ) levels and few, if any, other islet-enriched transcription factors were reduced in $\beta$ TC-3 nuclear extract prepared in the absence of DTT. IB, immunoblotting; SS, antibody super-shifted complex.

factors in $\beta$ TC-3 nuclear extracts prepared in the absence of DTT (Figure 3D). These results clearly illustrate the increased sensitivity of MAFA to oxidative stress changes. In addition, the ability to produce the dysfunctional (MAFA) $)_{2}$ species in both HeLa and $\beta$ TC-3 extracts suggests that intact $\beta$ cell sensitivity reflects differences in antioxidant defense mechanisms compared with non- $\beta$ cells.

NKX6.1 and PDX1 are also inactivated by $\mathrm{H}_{2} \mathrm{O}_{2}$ treatment in $\beta$ cell lines. Previous studies have shown that only nuclear MAFA levels, and not PDX1 levels, are reduced in diabetic $d b / d b$ mouse islets $(5,42)$. Furthermore, PDX1 gel-shift binding activity is not decreased in these extracts when compared with normoglycemic controls (43). However, since Mafa ${ }^{\Delta P a n c}$ mice are euglycemic (18), the loss of this transcription factor alone would not cause hyperglycemia in $d b / d b$ mice $(5,44)$. Thus, we next screened to determine whether the subcellular distribution and/or activity of other islet-enriched transcription factors was sensitive to $\mathrm{H}_{2} \mathrm{O}_{2}$ exposure in $\beta$ cell lines. Strikingly, in addition to the positive indicators of oxidative stress, MAFA and FOXO1, only the nuclear content of the islet $\beta$ cell-enriched NKX6.1 transcription factor was affected (Figure 4A). MAFA was more responsive to $\mathrm{H}_{2} \mathrm{O}_{2}$ than was NKX6.1, as nearly $90 \%$ was in the cytoplasm compared with approximately $60 \%$ for NKX6.1. In addition, immunostaining also showed NKX6.1 translocation to the cytoplasm and few other islet-enriched transcription factors or cofactors (Figure 4B and Supplemental Figure 2). The oxidative stressinduced increase in NKX6.1 SDS-PAGE mobility also resulted from dephosphorylation (Figure 4A and Supplemental Figure $1 \mathrm{C})$, and like MAFA, the phosphosite mutants did not prevent cytoplasmic accumulation in $\mathrm{H}_{2} \mathrm{O}_{2}$-treated $\beta$ TC-3 cells (Supplemental Figure 1, D and E).

Altered PDX1 activity is commonly associated with $\beta$ cell dysfunction under chronically high glucose conditions, as revealed by loss of in vitro gel-shift binding ability in diabetic ZDF rat islets and HIT-T15 $\beta$ cell extracts (4). However, nuclear PDX1 levels were unchanged in $\mathrm{H}_{2} \mathrm{O}_{2}$-treated $\beta$ TC-3 cells (Figure 4A), with protein removed from the nuclear periphery during extraction being the probable source of the control and experimental cytoplasmic signal (37). ChIP assays were next performed to determine whether nuclear PDX1-binding activity to endogenous target gene promoter sequences was impacted by $\mathrm{H}_{2} \mathrm{O}_{2}$ in $\beta \mathrm{TC}-3$ cells. The time course of inactivation was indistinguishable between PDX1, MAFA, and NKX6.1 (Figure 4C), implying that these stress conditions had a similar negative effect on endogenous promoter-binding ability. In contrast, the endogenous binding ability of other islet-enriched transcription factors was unchanged (Figure 4C). Collectively, these cell line-based experiments provide insight into both the complexity and selectivity of islet-enriched transcription factor inactivation under conditions simulating those of T2DM in vivo.

Nuclear NKX6.1 levels are profoundly reduced in diabetic $d b / d b \beta$ cells and rescued by GPX1 expression. The $d b / d b$ mouse is a model of obesity and T2DM due to a deficiency in leptin receptor activity (45, 46). Translocation of FOXO1 to the nucleus is a barometer of oxidative stress in these mice (Figure 5B) $(41,42,47)$. The nuclear content of MAFA and NKX6.1 was drastically and specifically reduced in islet $\beta$ cells of hyperglycemic 10 -week-old $d b / d b$ mice, seen both by immunostaining and immunoblotting (WT mice blood glucose levels were $163 \pm 22 \mathrm{mg} / \mathrm{dl}$; $d b / d b$ mice blood glucose levels were $500 \pm 73$ ) (Figure 5). As observed in $\mathrm{H}_{2} \mathrm{O}_{2}$-treated $\beta$ cell lines, the nuclear levels of many other transcription factors and coregulators were unchanged in $d b / d b$ islets (Figure 5A and Supplemental Figure 2). Islet $\beta$ cell function and nuclear MAFA content were rescued upon transgenic expression of Gpx1 in $d b / d b$ mice (5), which functions to detoxify the $\mathrm{H}_{2} \mathrm{O}_{2}$ generated under hyperglycemic conditions. Gpx1 expression also returned NKX6.1 and GLUT2 subcellular levels to normal (Figure 6); GLUT2 is the $\beta$ cell's principal glucose transporter and is MAFA regulated (17). Of significant note, NKX6.1 affects adult $\beta$ cell function more pro- 
A

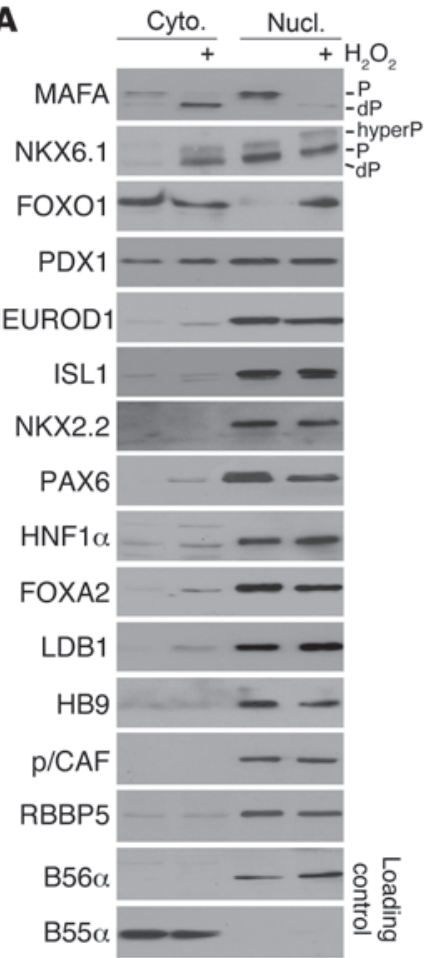

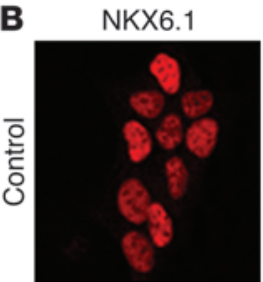
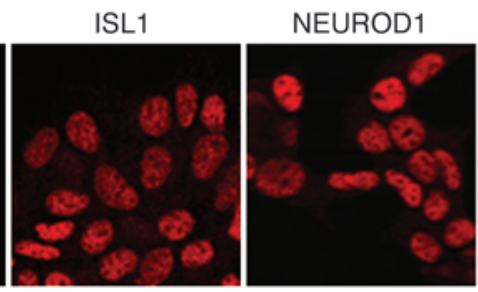

myc-NKX6.1

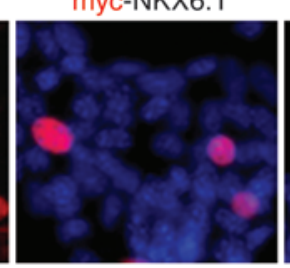

myc-ISL1
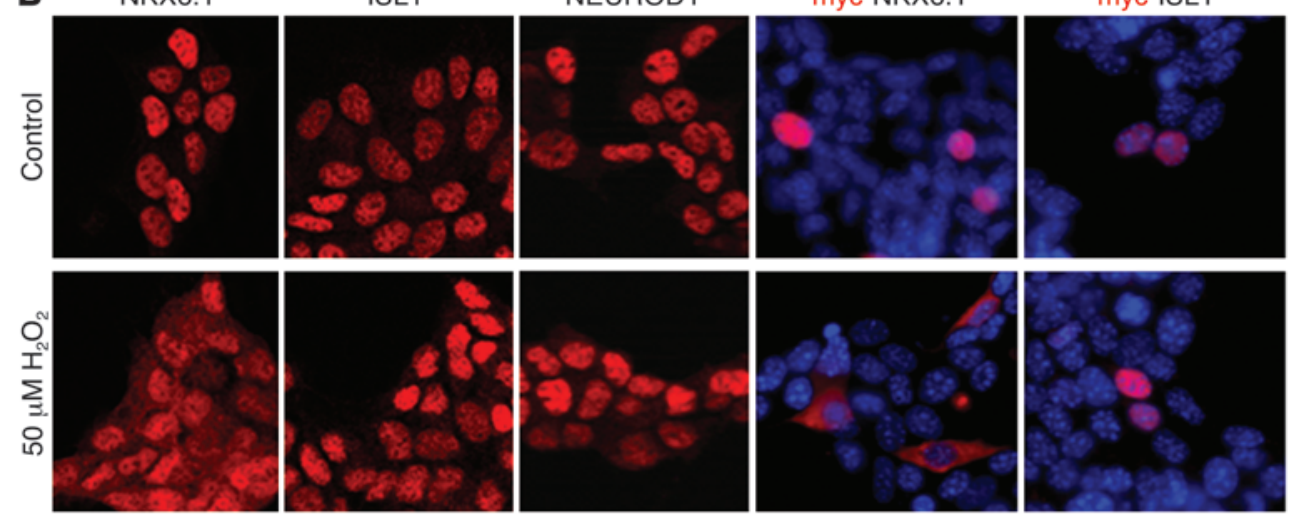

C

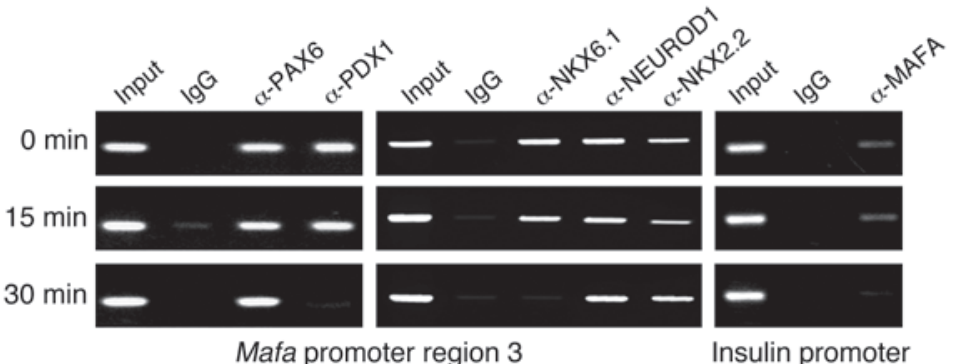

Figure 4

NKX6.1 and PDX1 are also inactivated in $\mathrm{H}_{2} \mathrm{O}_{2}$-treated $\beta$ TC-3 cells. (A) Cytoplasmic and nuclear distribution of a variety of regulatory factors in $\beta$ TC-3 cells treated with or without $\mathrm{H}_{2} \mathrm{O}_{2}$ for 90 minutes. The change in NKX6.1 and MAFA mobility and subcellular localization is shown by immunoblotting, with levels quantitated using NIH ImageJ software. Dephosphorylation causes MAFA (35) and NKX6.1 to run at a faster mobility on SDS-PAGE (see also Supplemental Figure 1C). (B) Immunostaining shows endogenous or myc-tagged transfected NKX6.1, ISL1, and/or NEUROD1 subcellular localization in control and treated cells. (C) Oxidative stress results in the specific loss of endogenous MAFA, NKX6.1, and PDX1 binding to target gene regulatory sequences in ChIP assays. hyperP, hyperphosphorylated.

foundly than MAFA, with overt hyperglycemia observed within days of deletion in adult $P d x 1-C r e^{E R} ; N k \times 6.1^{f /-}$ mice (B. Taylor and M. Sander, unpublished observations).

Islet $\beta$ cell proliferation precedes the sequential loss of nuclear MAFA and NKX6.1 in $\mathrm{db} / \mathrm{db}$ mice. Elevated blood glucose levels are first observed at 4 weeks, and hyperglycemia plateaus at around 12 weeks in $d b / d b$ mice (5). The early rise in glucose is due to insulin resistance primarily in muscle, liver, and adipose tissues. A normal response to conditions of reduced peripheral insulin sensitivity, also seen during pregnancy, is increased $\beta$ cell proliferation to improve insulin availability (48-51). Here we have compared the temporal change in MAFA, NKX6.1, and FOXO1 levels with $\beta$ cell proliferation in 4-, 6-, 8-, and 10-week-old $d b / d b$ mice. The early nuclear activation of FOXO1 protects $\beta$ cells against oxidative damage, in part, through stimulation of Mafa expression (41).

Immunostaining results showed that FOXO1 nuclear translocation occurs at around 6 weeks (Supplemental Figure 3), preceding the major changes in MAFA and NKX6.1 nuclear content at 8 and 10 weeks, respectively (Figure 7, A and B). The loss of GLUT2 levels closely correlated with the decrease in MAFA (Supplemental Figure 3), an expected result considering the importance of MAFA to Glut2 expression (17). Notably, increases in $\beta$ cell proliferation preceded FOXO1 nuclear translocation, as more than $20 \%$ of 4 -weekold insulin-positive cells were positive for Ki67, a cell replication marker (Figure 7C). However, only $1 \%$ of these cells were still Ki67 ${ }^{+}$ by 6 weeks. These results indicated that an initial stress signal(s) in $d b / d b$ mice mediates adaptive $\beta$ cell expansion and FOXO1 translocation (41), while hyperglycemia and oxidative stress lead to $\beta$ cell dysfunction by targeting MAFA and then NKX6.1.

MAFA, MAFB, PDX1, and NKX6.1 levels are decreased in buman T2DM islet $\beta$ cells. The data collected in animal models of T2DM suggest that $\beta$ cell dysfunction could reflect the loss of MAFA (5) and NKX6.1 (Figure 5) in $d b / d b$ mice or MAFA and PDX1 in ZDF rats (4). Islets from 8 normal control and 8 T2DM donors were obtained to examine whether a similar association existed in humans. As expected, the T2DM islets had poorer glucose-stimulated insulin secretion properties than the normal controls (Supplemental Figure 4A). The mRNA and protein levels of human MAFA, MAFB, PDX1, and NKX6.1 were compared with a variety of transcription factors unaffected by oxidative stress in $\beta$ cell lines and $d b / d b$ islets. MAFB was also assessed, since this large MAF factor is coexpressed with MAFA in human islet $\beta$ cells $(52,53)$, a situation not found in rodents $(38,54)$. In addition, we also analyzed NEUROGENIN3 (i.e., NEUROG3), OCT4 (POU5F1), NANOG, and L-MYC (MYCL1) levels, transcription factors associated with progenitor cell development that were induced in islet $\beta$ cells of T2DM animal models, including $d b / d b$ mice (47).

Steady-state MAFA, MAFB, NKX6.1, and PDX1 mRNA and protein levels were significantly lower in human T2DM islets, whereas no difference was observed in HNF1 $\alpha$, ISL1, and NEUROD1 (Figure 8, 
A
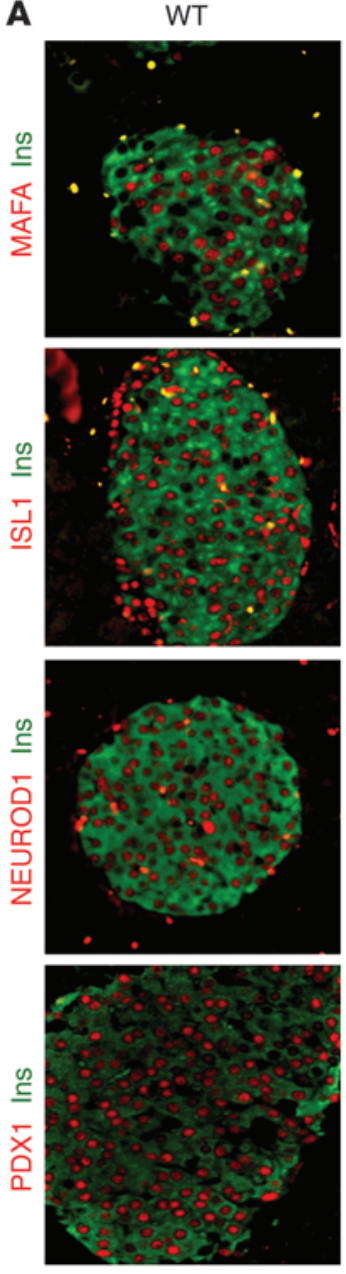
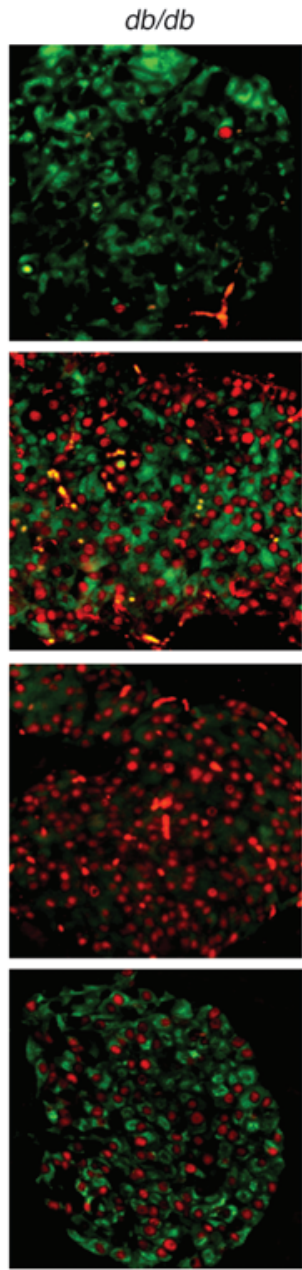

B
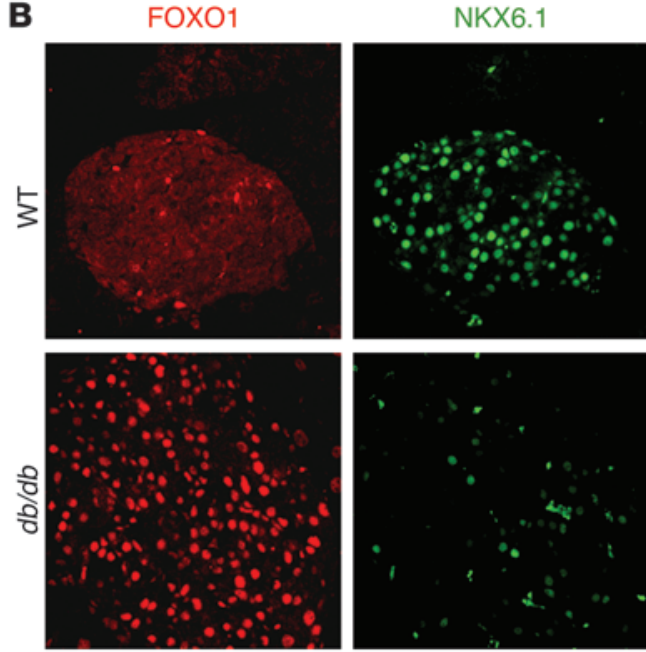

Merge Ins (white)
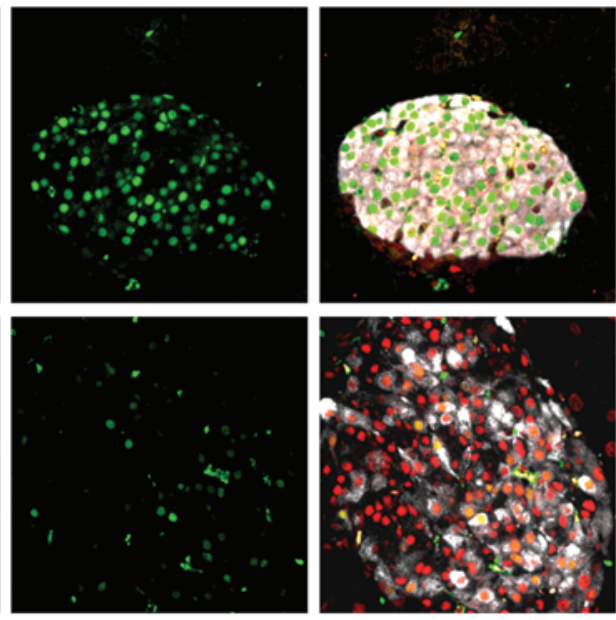

C
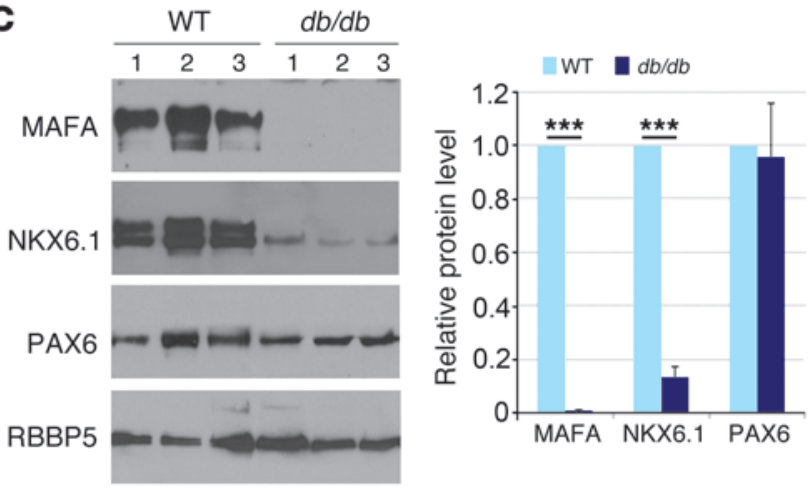

Figure 5

Nuclear NKX6.1 levels are profoundly reduced in diabetic $d b / d b$ islet $\beta$ cells. (A) Immunostaining for MAFA, ISL1, NEUROD1, PDX1, and insulin in 10-week-old WT and $d b / d b$ mouse pancreas. (B) FOXO1, NKX6.1, and insulin immunosignals in WT and diabetic $d b / d b$ pancreas. (C) Immunoblotting of MAFA and NKX6.1 in islet extracts prepared from 10-week-old WT and $d b / d b$ mice $(n=3)$. Quantified MAFA, NKX6.1, and PAX6 levels were normalized to RBBP5. The relative change in each $d b / d b$ mouse was compared with 3 controls. ${ }^{* \star} P<0.001$.

A and B). As predicted, the expression level of many physiologically important genes activated by these factors was compromised in T2DM islets, including insulin, glucose transporter type 1 (SLC2A1), and GLP1 receptor (Figure $8 \mathrm{C}$ ). However, the protein levels and/or nuclear distribution of factors unaffected in $\mathrm{H}_{2} \mathrm{O}_{2}$-treated $\beta$ TC-3 cells and/or hyperglycemic $d b / d b$ mice were also unaltered in human T2DM islets (Figure 8B and Supplemental Figure 4B). Moreover, there was no change in mRNA expression levels in human T2DM islets of the progenitor markers induced in rodents (see NEUROG3, POU5F1, NANOG, and MYCL1 in Figure 8A).

A profound loss of MAFA, MAFB, PDX1, and NKX6.1 protein levels was also revealed upon quantitation of nuclear $\beta$ cell staining (Figure 8D). Furthermore, the MAFB nuclear content was reduced to a similar low level in human islet $\alpha$ cells (i.e., normal, $53 \pm 7.2 \%$ of glucagon-positive cells and only $1.51 \pm 2.3 \%$ in T2DM; Supplemental Figure 5A), whereas no change was observed in diabetic $d b / d b$ islet $\alpha$ cells (Supplemental Figure 5B). Collectively, our analysis of $\beta$ cell lines, the $d b / d b$ mice, and human T2DM islets illustrates that disease stress conditions cause the selective loss of
MAFA, MAFB, NKX6.1, and/or PDX1, which we propose plays a principal role in compromising $\beta$ cell function in T2DM.

\section{Discussion}

Oxidative stress induces modifications within proteins, and these modifications impact activity $(55,56)$, stability $(57,58)$, and/or subcellular distribution $(40,41)$. Such conditions are also induced within T1DM and T2DM islets, contributing to $\beta$ cell dysfunction. In this study, $\beta$ cell lines, $d b / d b$ mice, and human T2DM islets were used to determine whether a fundamental cause of $\beta$ cell dysfunction was a result of loss in islet-enriched transcription factor activity. Our results suggest that the $\beta$ cell's inability to produce sufficient insulin to overcome the resistance of peripheral tissues is caused by the gradual loss of a specific subset of transcription factors essential to glucose sensing and insulin secretion. Specifically, we propose that MAFA (and/or MAFB) represents early and very sensitive targets of oxidative stress, potentially manifested as postprandial hyperglycemia in human prediabetics $(59,60)$. Subsequent damaging events in NKX6.1 and/or PDX1 generated over 
A
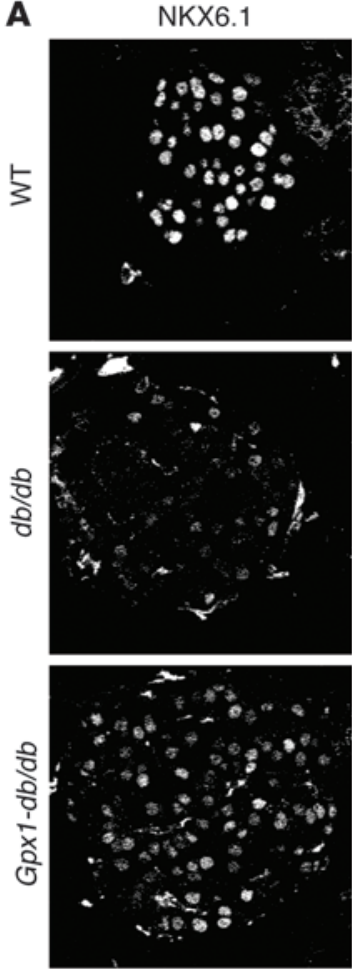

PAX6
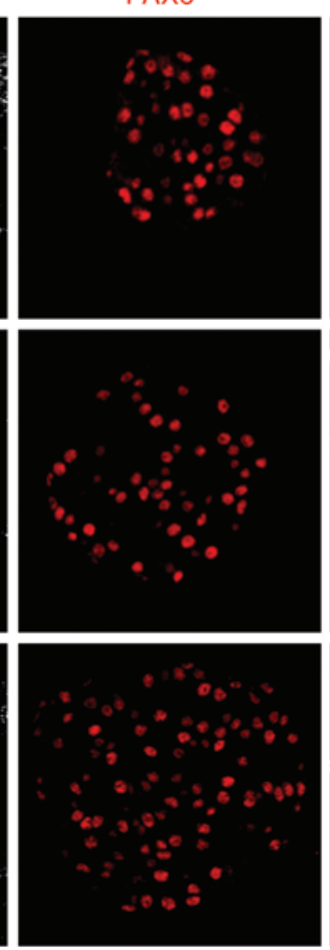

Merge Ins
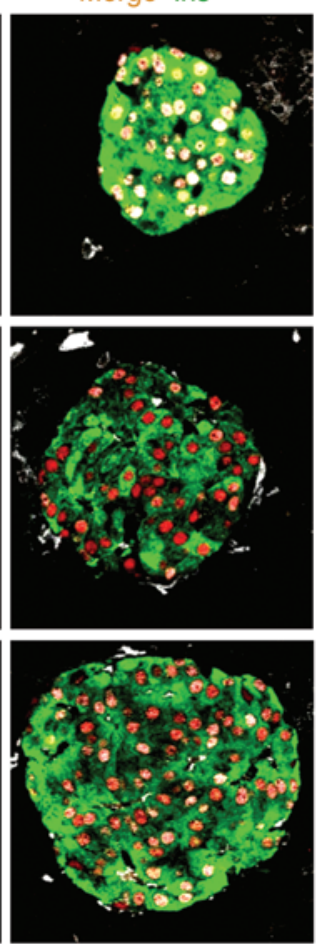

B
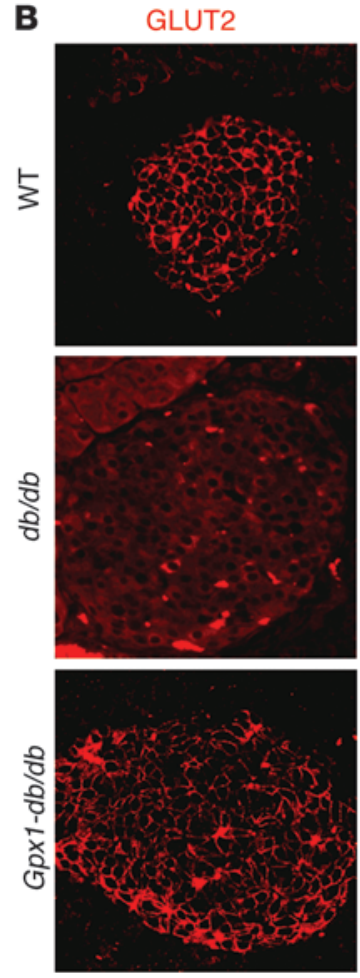

GLUT2 Ins
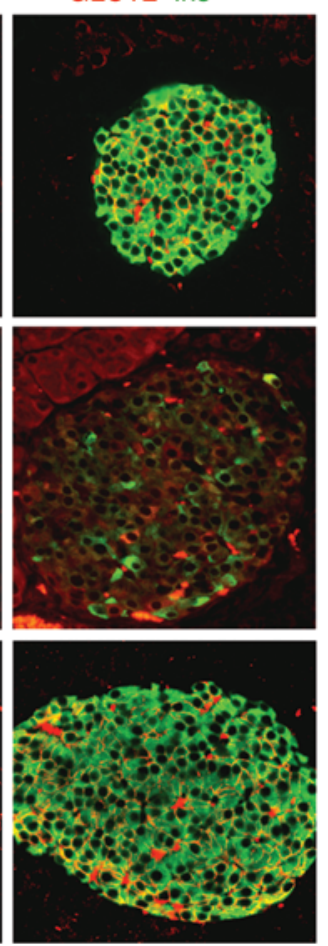

Figure 6

NKX6.1 and GLUT2 subcellular levels are rescued by transgenic Gpx1 expression in $d b / d b$ islet $\beta$ cells. Immunostained images of (A) NKX6.1, PAX6, and (B) GLUT2 in 20-week-old WT, $d b / d b$, and Gpx1- $d b / d b$ pancreas.

the course of many years lead to disease progression, drastically reducing insulin production and causing overt diabetes (Figure 9).

Several islet-enriched transcription factors have been linked to MODY (e.g., HNF4 $\alpha$ [MODY1], HNF1 $\alpha$ [MODY3], PDX1 [MODY4], NEUROD1 [MODY6]) $(15,61)$, a rare autosomal dominant form of diabetes. With the exception of PDX1, we found that these transcription factors and many others were unaffected by diabetic stress conditions in human or rodent $\beta$ cells. This included gene products associated with progenitor cell formation recently found produced by physiological pressures such as multiparity and aging in mice lacking FOXO1 in $\beta$ cells (47). Thus, lineage-tracing analysis showed that hyperglycemia imposed by such conditions caused $\beta$ cells to become insulin ${ }^{-}$NEUROG3 $^{+}$L-MYC $^{-}$ $(\mathrm{MYCL} 1)^{+} \mathrm{NANOG}^{+} \mathrm{OCT} 4$ (POU5f1) ${ }^{+}$, described as dedifferentiation to an endocrine progenitor-like stage. In contrast, we did not detect any changes in NEUROG3, POU5F1, NANOG, or MYCL1 levels in human T2DM islets (Figure 8A), presumably because such changes do not occur during the progression of the disease. However, our results are consistent with the view that FOXO1 plays an early and influential role in the gradual decline of $\beta$ cell function, preceding the loss of MAFA and MAFB.

MAFB is expressed in both $\alpha$ and $\beta$ cells in human islets $(52,53)$, but is silenced in rodent $\beta$ cells soon after birth $(18,38)$. It is not only essential for glucagon and insulin transcription in the development of $\alpha$ and $\beta$ cells, but also for adult gene products required for glucose sensing and hormone secretion $(18,38)$. Postnatal repression of MAFB and the predominance of MAFA appear to be required for rodent $\beta$ cell maturation (38), while it is unknown what impact the coexpression of MAFA and MAFB has on human islet cells.
Both MAFA and MAFB were compromised to a similar low level in human T2DM $\beta$ cells (Figure 8D and Supplemental Figure 5) and transfected $\mathrm{H}_{2} \mathrm{O}_{2}$-treated $\beta \mathrm{TC}-3$ cells (Figure $2 \mathrm{E}$ ). However, MAFB mRNA and protein expression was only affected in human T2DM islet $\alpha$ cells (Figure 8 and Supplemental Figure 5). It will be interesting to explore whether this reduction in MAFB contributes to dysregulated glucagon secretion in human T2DM patients (62).

In contrast to the MODY proteins, whose inactivation results from coding region mutations, our studies suggest that transcription factor dysfunction can also be caused by environmental factors. Oxidative stress likely represents a principal means of disabling $\beta$ cells in T2DM, as deduced by the posttranslational modifications commonly found (63) and the effectiveness of antioxidants at improving cell function $(5,14)$. Moreover, using a transgenic model, we showed that Gpx1 restored NKX6.1 nuclear levels under circumstances that also improved blood glucose homeostasis and MAFA content (Figure 6). Significantly, Gpx1-db/db mice are still morbidly obese despite improved $\beta$ cell function (5), so the damaging signals leading to cell dysfunction continue being produced from insulin-resistant peripheral tissues.

Although precisely how MAFA, MAFB, NKX6.1, or PDX1 become inoperative in vivo is unclear, both the $\mathrm{H}_{2} \mathrm{O}_{2}$ treatment data from $\beta$ cell lines and the time course analysis in $d b / d b$ mice strongly suggest that MAFA is more sensitive to this stressor than NKX6.1. Moreover, earlier work also indicates that MAFA activity precedes the loss of PDX1 during glucotoxicity (23). The initial step of MAFA and MAFB inactivation appears to be the formation of a DNA-binding defective covalent dimer species, as shown upon incubation of MAFA containing HeLa and $\beta$ TC-3 cell extracts with 
A

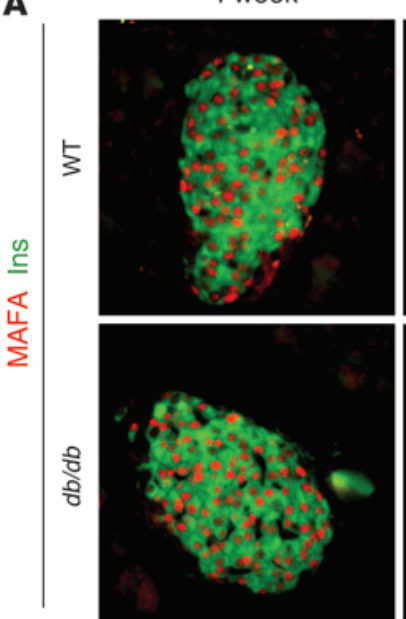

B

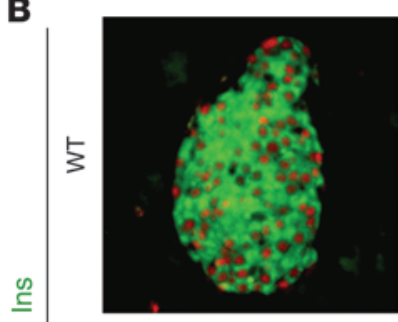

불

$\frac{0}{8}$

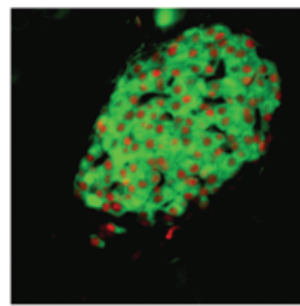

C

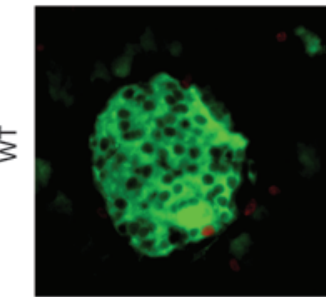

魚

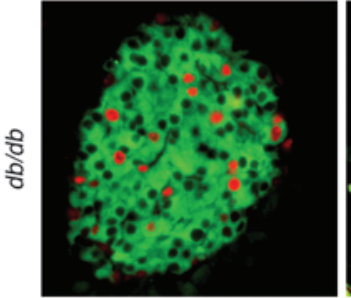

6 week
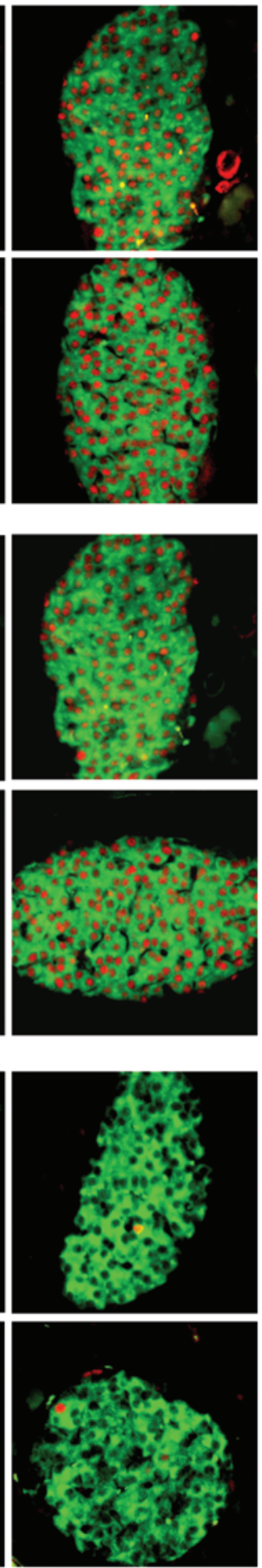

8 week
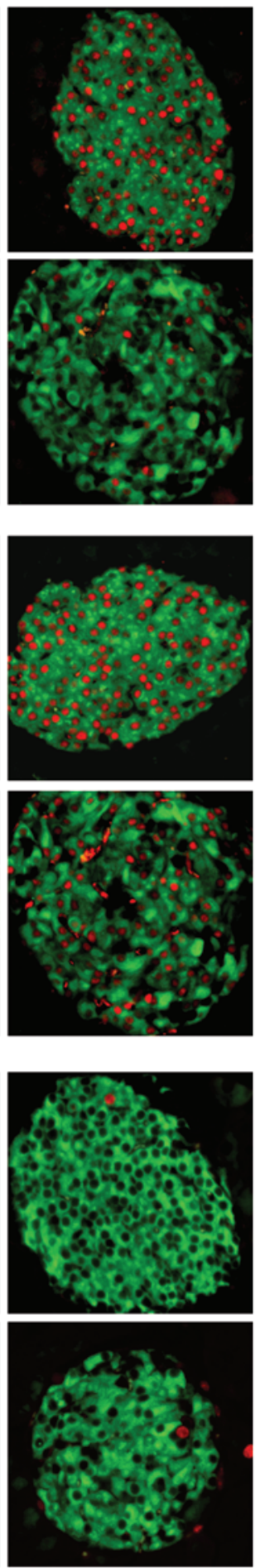

10 week
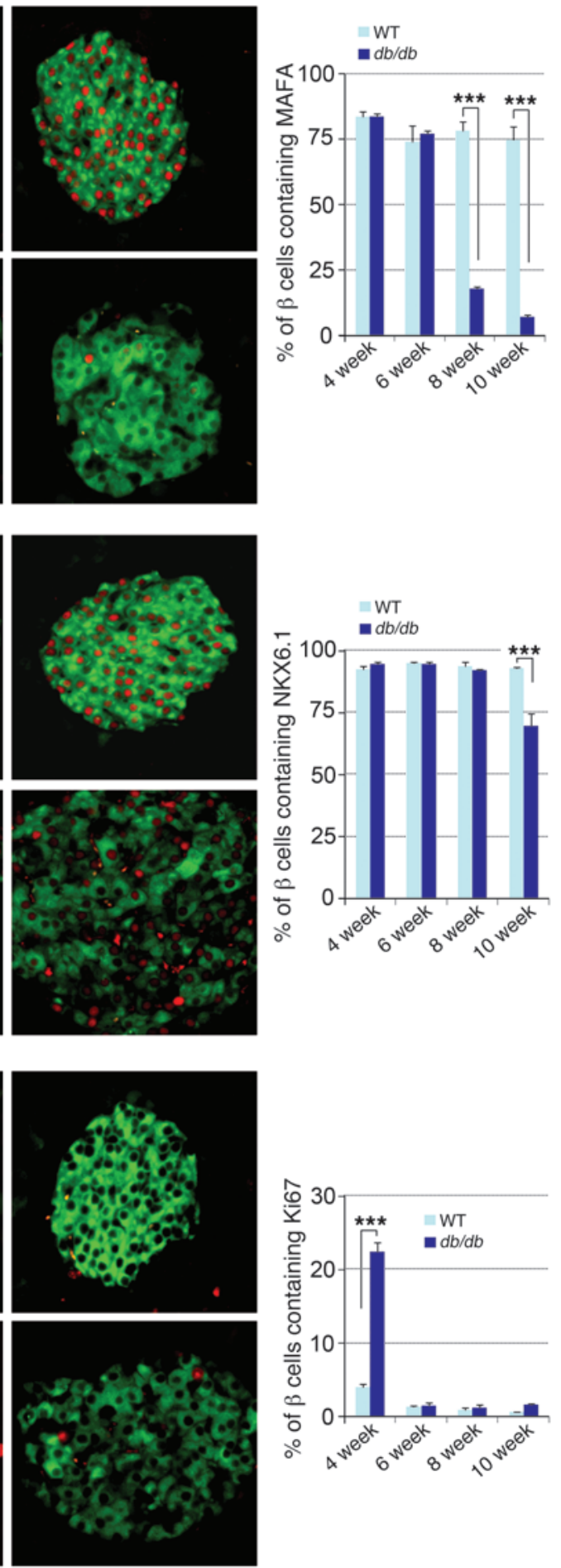

Figure 7

Islet $\beta$ cell proliferation precedes the loss of MAFA and NKX6.1 in $d b / d b$ islets of (A) MAFA, (B) NKX6.1, and (C) Ki67 in 4-, 6-, 8-, and 10-week-old WT and $d b / d b$ pancreas. Quantification of the percentage of insulin-positive $(\beta)$ cells costaining for MAFA, NKX6.1, and Ki67 is shown $(n=4) .{ }^{* \star *} P<0.001$. 
A

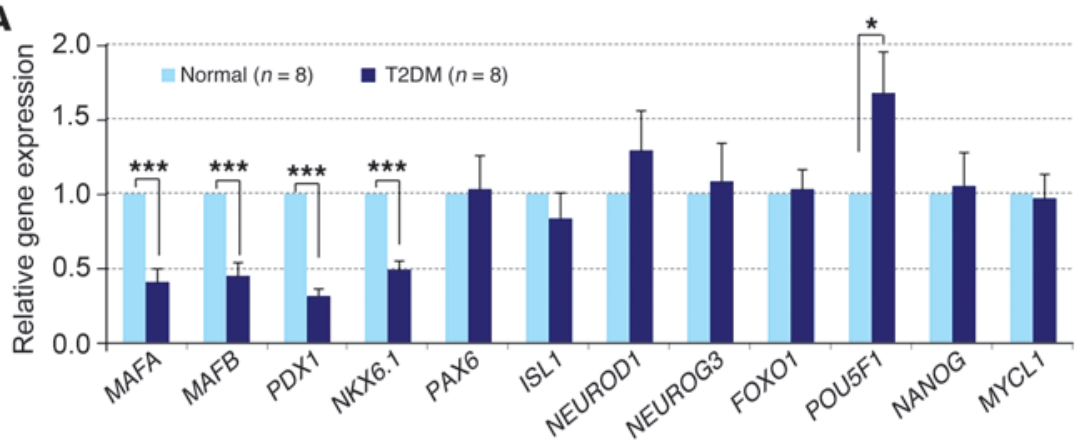

B

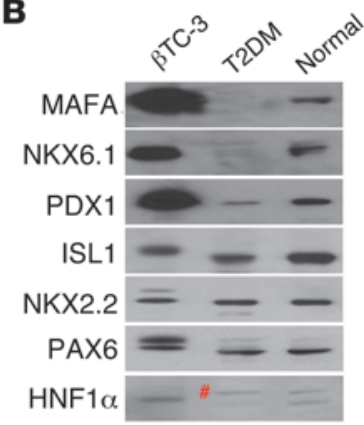

C

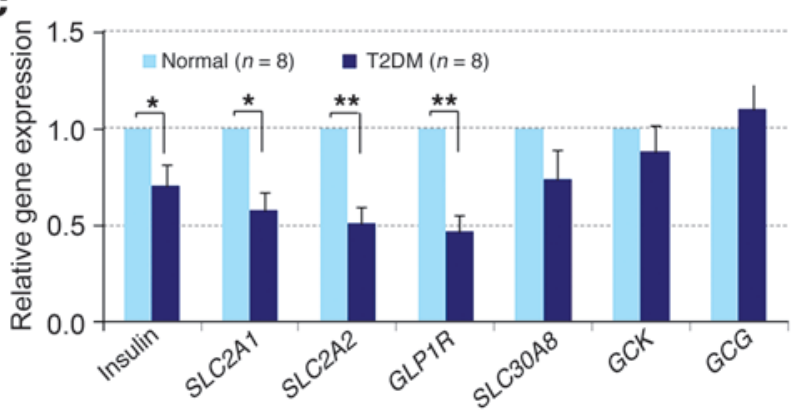

D
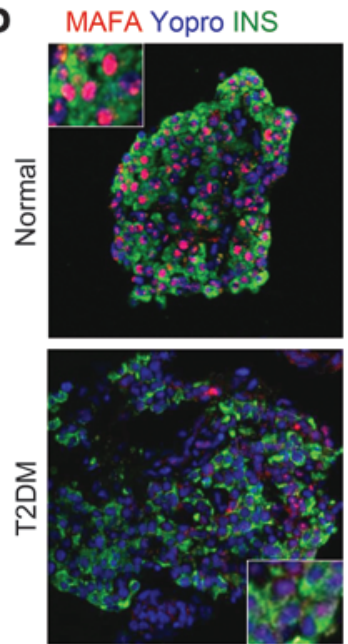

NKX6.1 Yopro INS
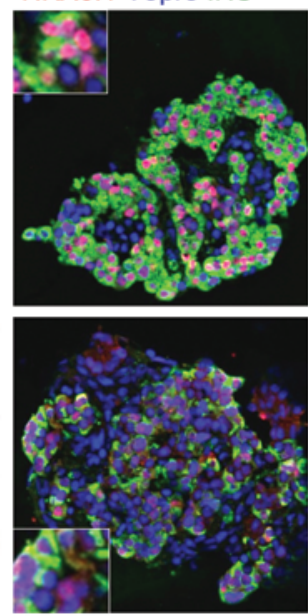

PDX1 Yopro INS
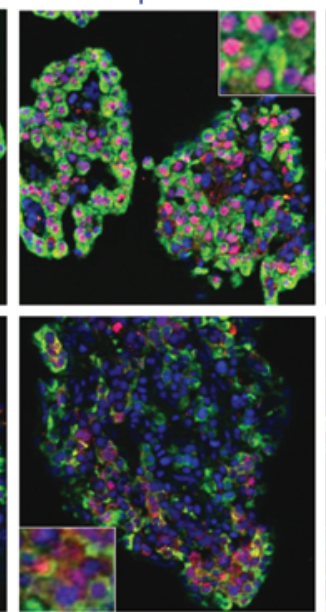

MAFB Yopro INS

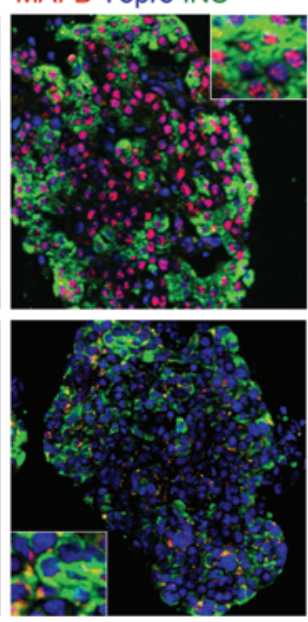

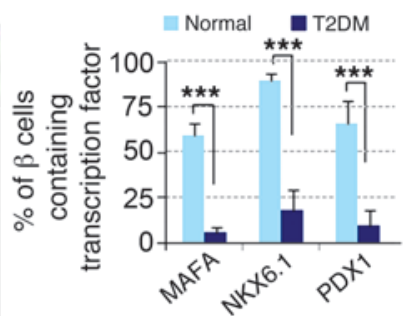

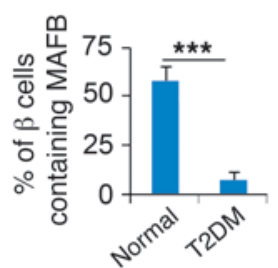

Figure 8

MAFA, MAFB, NKX6.1, and PDX1 expression levels are compromised in human T2DM islet $\beta$ cells. (A and C) Real-time PCR analysis of normal human and T2DM human islets. (B) MAFA, PDX1, and NKX6.1 protein levels were reduced in human T2DM islets when compared with other islet-enriched transcription factors. \#Predicted molecular weight of human HNF1 $\alpha$. (D) Reduction in MAFA, NKX6.1, PDX1, and MAFB in human T2DM islet insulin-positive cells by immunostaining. Quantification of the percentage of $\beta$ cells containing nuclear MAFA, NKX6.1, PDX1, and MAFB is shown. ${ }^{\star} P<0.10 ;{ }^{\star *} P<0.01 ;{ }^{* \star *} P<0.001$.

$\mathrm{H}_{2} \mathrm{O}_{2}$ alone or in the absence of the DTT antioxidant (Figure 3). Notably, these conditions did not affect PDX1 SDS-PAGE mobility or DNA-binding properties. A future objective will be to determine whether (MAFA) $)_{2}$ can be detected during $\beta$ cell inactivation in vivo, which was probably undetectable here due to the relatively long time window between $d b / d b$ sample collections (i.e., 1 week) and the limited availability of human T2DM samples. In addition, we are working to determine how oxidative stress leads to PDX1 and NKX6.1 incapacitation, presumably through oxidation at lysines, cysteines, and/or histidines found to be targeted in islet $\beta$ cell proteins in diabetic GK rats (64).
An important feature of our findings was how selectively MAFA, MAFB, PDX1, and NKX6.1 were deactivated as compared with other key islet regulators in T2DM $\beta$ cells (Figure 8, A and D, and Supplemental Figure 4B). Such findings strongly suggest that the decrease in glucose-stimulated insulin secretion properties in these islets (Supplemental Figure 4A) primarily results from reduced levels of these key transcriptional regulators. Moreover, we propose that their progressive decline leads to both " $\beta$ cell exhaustion" and loss of insulin-positive cell mass associated with T2DM (65). We postulate that restoring the activity of these transcription factors is critical to the improved $\beta$ cell function and blood 
Metabolic (oxidative) stress

Blood glucose level

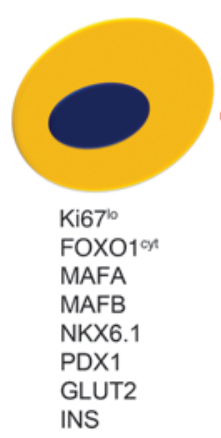

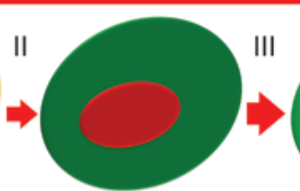

Ki67 $7^{10}$

FOXO1 ${ }^{\text {nuc }}$

MAFA

MAFB

NKX6.1

PDX1

GLUT2

INS glucose control observed within weeks after bariatric surgery in T2DM patients $(66,67)$, a proposal supported by the increase in PDX1 protein levels seen upon recovery (66). It is also striking that human embryonic stem cell-derived insulin-positive cells produced in vitro are dysfunctional and fail to express NKX6.1, PDX1, and MAFA (68-70). Consequentially, the identification of small molecules that increase expression and/or restore the nuclear content of these transcription factors could be very useful in T2DM treatment as well as in generating $\beta$ cells for T1DM therapy.

\section{Methods}

DNA constructs. MAFA C277/293A, MAFA C42/59/69S, as well as all of the other MAFA and MAFB mutants described in Supplemental Figure 1, were prepared in a cytomegalovirus-driven (CMV-driven) pCMV4-myc vector using the the primers listed in Supplemental Table 1 and the QuikChange site-directed mutagenesis kit (Stratagene, Agilent Technologies) (35).

$\mathrm{H}_{2} \mathrm{O}_{2}$ treatment, cellular fractionation, and immunoblotting analysis. HeLa (71), $\alpha$ TC-6 (72), MIN6 (73), and $\beta$ TC-3 (74) cells were grown as described. $\mathrm{H}_{2} \mathrm{O}_{2}$-treated cells were resuspended in lysis buffer $(100 \mathrm{mM}$ Tris- $\mathrm{HCl}$, $\mathrm{pH} 8.0,0.5 \%$ NP-40), with the centrifuged supernatant serving as the cytoplasmic fraction. The pellet was suspended in extraction buffer $(20 \mathrm{mM}$ HEPES, pH 7.4, 400 mM NaCl, 1 mM EGTA, 1 mM EDTA, 2 mM DTT, and $1 \times$ Protease inhibitor [Roche]), with the centrifuged supernatant serving as the nuclear fraction. Isolated islets were suspended in passive lysis buffer $(0.15 \mu \mathrm{l} /$ islet; Promega), and the supernatant protein was obtained after sonication and centrifugation. Adenovirus-expressed catalase was provided by Chris Rhodes (University of Chicago, Chicago, Illinois, USA), and infection of $\beta$ TC-3 and MIN6 cells occurred prior to $\mathrm{H}_{2} \mathrm{O}_{2}$ treatment. Proteins ( $10 \mu \mathrm{g}$ loaded) were separated by $10 \%$ SDS-PAGE and tested by immunoblotting with the following antibodies: rabbit $\alpha$-MAFA (Bethyl Laboratories, 1225, 1:2,000); mouse $\alpha$-NKX6.1 (Developmental Studies Hybridoma Bank, 1:2,000); mouse $\alpha$-ISL1 (Developmental Studies Hybridoma Bank, 1:1,000); goat $\alpha$-HNF1 $\alpha$ (Santa Cruz Biotechnology, 1:1,000); goat $\alpha$-FOXA2 (Santa Cruz Biotechnology, 1:1,000); goat $\alpha$-B56 $\alpha$ (Santa Cruz Biotechnology, 1:1,000); goat $\alpha$-LDB1 (CLIM-2) (Santa Cruz Biotechnology, 1:1,000); rabbit $\alpha$-NEUROD1 (Epitomics, 1:1,000); mouse $\alpha$-p/CAF (Santa Cruz Biotechnology, 1:1,000); mouse $\alpha$-RBBP5 (RBQ3) (Santa Cruz Biotechnology, 1:1,000); mouse $\alpha$-HB9 (Developmental Studies Hybridoma Bank, 1:1,000); mouse $\alpha$-NKX2.2 (Developmental Studies Hybridoma Bank, 1:1,000); rabbit $\alpha$-PDX1 (provided by Chris Wright, Vanderbilt University, Nashville, Tennessee, USA; 1:10,000); rabbit $\alpha$-PAX6

\section{Figure 9}

Events leading up to islet $\beta$ cell dysfunction in T2DM. Adaptive responses: (I) $\beta$ cell replication and (II) FOXO1 nuclear localization (41). Stress responses: (II) FOXO1 nuclear localization/inactivation (47) and sequential loss of (III) MAFA (and/or MAFB), and (IV) NKX6.1 (and/or PDX1) in response to hyperglycemia and oxidative stress. These circumstances lead to a decline in $\beta$ cell function, also termed "the stunned $\beta$ cell" (65).
(Covance, 1:1,000); mouse $\alpha$-B55 $\alpha$ (Santa Cruz Biotechnology, 1:1,000); rabbit $\alpha$-FOXO1 (Cell Signaling Technology, 1:1,000); HRP-conjugated $\alpha$-rabbit IgG (Promega, 1:2,000); and HRP-conjugated $\alpha$-mouse IgG (Promega, 1:2,000). The experiments were performed at least 3 times, with representative results quantitated using NIH ImageJ software.

DNA binding assays. Nuclear extracts were prepared from $\beta$ TC- 3 or HeLa cells transfected using the Lipofectamine reagent (Invitrogen) with myc-tagged MAF plasmids as described previously (75), except DTT was not added to the extraction buffer. MAFA was tested for DNA-binding activity with ${ }^{32} \mathrm{P}-$ labeled rat insulin II C1 element (-126TGGAAACTGCAGCTTCAGCCCCTCTG ${ }^{-101}$ ) (76), and PDX1 with Mafa region 3 site (-8087ATTACCCATTTCTGTTAATTTGTTCTGGA-8063) (75). HeLa nuclear extract was also prepared from cells transfected with myc-MAFA, myc-MAFA C277/293A, or myc-MAFA C42/59/69S in the presence of $20 \mathrm{mM}$ of dithiothreitol (DTT) and then treated with increasing concentrations of $\mathrm{H}_{2} \mathrm{O}_{2}$.

Immunostaining analysis. $\beta$ TC-3, $\alpha$ TC-6, or HeLa cells were cultured on cover slides and either analyzed directly or transfected overnight with 0.5 $\mu \mathrm{g}$ of DNA using the Lipofectamine reagent (Invitrogen). The cells were treated for 90 minutes in MEM containing either $50 \mu \mathrm{M} \mathrm{H}_{2} \mathrm{O}_{2}$ ( $\beta \mathrm{TC}-3$ cells), $100 \mu \mathrm{M} \mathrm{H}_{2} \mathrm{O}_{2}$ ( $\alpha \mathrm{TC}-6$ cells), or $1 \mathrm{mM} \mathrm{H}_{2} \mathrm{O}_{2}$ (HeLa cells). Tissue fixation, embedding, and immunofluorescence labeling of WT, $d b / d b$, and Gpx1-db/db pancreas were performed as described previously (5). WT C57BLKS/J (000662) and $d b / d b$ homozygous (000642) BKS.Cg- $m^{+/+} L e p r^{d b} / \mathrm{J}$ mice were purchased from The Jackson Laboratory. Isolated human islets were embedded and immunostained as described (53). An islet cell was scored positive for nuclear factor only when at least $75 \%$ of the nucleus was surrounded by the cytoplasm labeled for a given hormone. Immunostaining was performed with the following antibodies: mouse $\alpha$-myc (9E10; Santa Cruz Biotechnology, 1:500); rabbit $\alpha$-MAFA (1:1,000), mouse $\alpha$-ISL1 (Developmental Studies Hybridoma Bank, 1:500); rabbit $\alpha$-MAFB (Bethyl Laboratories, 658, 1:1,000); mouse $\alpha$-NKX6.1 (1:2,000); mouse $\alpha$-NKX2.2 (1:1,000); rabbit $\alpha$-PAX6 (1:500); rabbit $\alpha$-FOXO1 (1:300); mouse $\alpha$-HB9 (1:500); goat $\alpha$-FOXA2 (1:1,000); rabbit $\alpha$-Ki67 (BD Pharmingen, 1:400); and rabbit $\alpha$-NEUROD1 (1:500). The secondary Cy2-, Cy3-, or Cy5-conjugated donkey $\alpha$-goat, $\alpha$-guinea pig, $\alpha$-rabbit, or $\alpha$-mouse IgGs were obtained from Jackson ImmunoResearch Laboratories. Immunofluorescence images were acquired using confocal microscopy (LSM510, Carl Zeiss) or immunofluorescence microscopy (Imager.M2, Carl Zeiss) and presented at a magnification of $\times 200$.

Human islet functional analysis. Islets were obtained from multiple isolation centers supported by the NIH, the Juvenile Diabetes Research Foundation (JDRF), the Islet Cell Resource Centers, and the Integrated Islet 
Distribution Program (http://iidp.coh.org). Islets were handpicked on the day of arrival and then cultured at $37^{\circ} \mathrm{C}$ for 24 hours in RPMI- 1640 containing $10 \% \mathrm{FBS}$ and $5 \mathrm{mM}$ glucose (53). Islet health was determined as described (53). Glucose-stimulated insulin secretion (GSIS) was evaluated in an islet perifusion apparatus using 2 secretagogues and 60 medium-size islets (77). Islet preparations were obtained from 8 normal and 8 T2DM cadaver donors: normal, 4 male and 4 female $(44.0 \pm 3.4$ years [range: 23 to 52 ], weight $74.8 \pm 5.1$ [range: 56 to 94 ], BMI $26.3 \pm 0.7$ [range: 24.3 to 29.4], cold ischemia time, $n=6,8.33 \pm 1.65$ hours [range: $1.5-13.5$ hours], and 2 unknown); T2DM, 4 male, 3 female, and 1 unknown (49.1 \pm 2.5 years [range: 38 to 59 ], weight $114 \pm 11.7$ [range: 71 to 168 ], BMI $37.3 \pm 2.9$ [range: 27 to 52.4 ], cold ischemia time, $n=5: 8.89 \pm 0.98$ hours [range: $6-12$ hours], and 3 unknown).

Quantitative RT-PCR analysis. Cellular RNA from human islets was isolated using the RNAqueous Phenol-free Total RNA Isolation Kit (Ambion). RNA assessment was determined in the Vanderbilt Functional Genomics Shared Resource Laboratory $(28 \mathrm{~S} / 18 \mathrm{~S}>1.4$, RNA integrity number $>8.2)$. DNA was removed with the TURBO DNA-free kit (Ambion). cDNA was prepared from RNA using the High Capacity cDNA Reverse Transcription Kit (Applied Biosystems), and quantitative PCR was performed using the One-Step system and TaqMan primers (Applied Biosystems). The experimental data were normalized to $\beta 2$ microglobulin, and relative mRNA changes were calculated by the comparative $\Delta \mathrm{Ct}$ method. Each T2DM sample was compared with the 8 controls. Minimum Information for Publication of Quantitative RealTime PCR Experiments (MIQE) guidelines were followed (78).

ChIP assay. $\beta$ TC-3 cells were formaldehyde cross-linked after $\mathrm{H}_{2} \mathrm{O}_{2}$ treatment, and the sonicated protein-DNA complexes were isolated under conditions described previously $(75,79)$. Sonicated chromatin was incubated for 12 to 14 hours at $4{ }^{\circ} \mathrm{C}$ with $\alpha$-MAFA, $\alpha$-PDX1, $\alpha$-PAX6, $\alpha$-NKX6.1, $\alpha$-NEUROD1, or $\alpha$-NKX2.2 antibody, and the complexes were isolated with protein A/G-agarose (Santa Cruz Biotechnology). PCR was performed on one-tenth of the purified immunoprecipitated DNA using 5 PRIME MasterMix (5 PRIME) and 15 pmol of the insulin (-378GGAACTGTGAAACAGTCCAAGG and ${ }^{-46}$ CCCCCTGGACTTTG CTGTTTG) and Mafa $\left({ }^{-8120}\right.$ CACCCCAGCGAGGGCTGATTTAATT and ${ }^{-7750}$ AGCAAG-
CACTTCAGTGTGCTCAGTG) transcriptional control region primers. The amplified products were resolved on a $1.4 \%$ agarose gel in Tris-acetate EDTA buffer containing ethidium bromide.

Statistics. Data are expressed as the means \pm SEM. $P$ values were calculated with a Student's 2-tailed test. Results were considered significant at ${ }^{*} P<0.10,{ }^{*} P<0.01$, or ${ }^{*} * P<0.001$.

Study approval. All studies involving the use of animals or human islets were approved by the IACUC or the IRB of Vanderbilt University Medical Center (Nashville, Tennessee, USA).

\section{Acknowledgments}

Chad Hunter helped to edit the manuscript. This work was supported by NIH grants (DK050203 and DK090570, to R. Stein; DK038325, to R.P. Robertson; DK66636, DK68854, DK72473, DK89572, and DK089538, to A.C. Powers; and DK068471, to M. Sander). This work was also supported by a Merit Review Award from the VA Research Service (BX000666, to A.C. Powers), as well as by grants from the JDRF (26-2008-863, to A.C. Powers; 3-2009555 , to S. Guo) and the Vanderbilt Diabetes Research and Training Center (DK20593). Imaging was performed with NIH support at the Vanderbilt University Medical Center's Cell Imaging Shared Resource (CA68485, DK20593, DK58404, HD15052, DK59637, and EY08126), and Vanderbilt University Medical Center's Islet Procurement and Analysis Core (DK20593). Human islets were obtained from the Integrated Islet Distribution Program, which is supported by the National Institute of Diabetes and Digestive and Kidney Diseases and the Juvenile Diabetes Research Foundation.

Received for publication March 29, 2013, and accepted in revised form May 1, 2013.

Address correspondence to: Roland Stein, Vanderbilt University Medical School, Department of Molecular Physiology and Biophysics, 723 Light Hall, Nashville, Tennessee 37232, USA. Phone: 615. 322.7026; Fax: 615.322.7236; E-mail: roland.stein@vanderbilt.edu.
1. Bottino R, Balamurugan AN, Bertera S, Pietropaolo M, Trucco M, Piganelli JD. Preservation of human islet cell functional mass by anti-oxidative action of a novel SOD mimic compound. Diabetes. 2002;51(8):2561-2567.

2. Gurgul E, Lortz S, Tiedge M, Jorns A, Lenzen S. Mitochondrial catalase overexpression protects insulin-producing cells against toxicity of reactive oxygen species and proinflammatory cytokines. Diabetes. 2004;53(9):2271-2280.

3. Kaneto H, et al. Beneficial effects of antioxidants in diabetes: possible protection of pancreatic beta-cells against glucose toxicity. Diabetes. 1999; 48(12):2398-2406.

4. Tanaka Y, Gleason CE, Tran PO, Harmon JS, Robertson RP. Prevention of glucose toxicity in HIT-T15 cells and Zucker diabetic fatty rats by antioxidants. Proc Natl Acad Sci U S A. 1999;96(19):10857-10862.

5 . Harmon JS, et al. $\beta$-Cell-specific overexpression of glutathione peroxidase preserves intranuclear MafA and reverses diabetes in $d b / d b$ mice. Endocrinology. 2009;150(11):4855-4862.

6. Hotta M, et al. Pancreatic beta cell-specific expression of thioredoxin, an antioxidative and antiapoptotic protein, prevents autoimmune and streptozotocin-induced diabetes. J Exp Med. 1998; 188(8):1445-1451.

7. Elsner M, Gehrmann W, Lenzen S. Peroxisome generated hydrogen peroxide as important mediator of lipotoxicity in insulin-producing cells. Diabetes. 2011;60(1):200-208.
8. Del Guerra S, et al. Functional and molecular defects of pancreatic islets in human type 2 diabetes. Diabetes. 2005;54(3):727-735.

9. Lupi R, et al. Insulin secretion defects of human type 2 diabetic islets are corrected in vitro by a new reactive oxygen species scavenger. Diabetes Metab. 2007;33(5):340-345.

10. Grankvist K, Marklund SL, Taljedal IB. CuZnsuperoxide dismutase, $\mathrm{Mn}$-superoxide dismutase, catalase and glutathione peroxidase in pancreatic islets and other tissues in the mouse. Biochem J. 1981; 199(2):393-398.

11. Tiedge M, Lortz S, Drinkgern J, Lenzen S. Relation between antioxidant enzyme gene expression and antioxidative defense status of insulin-producing cells. Diabetes. 1997;46(11):1733-1742.

12. Piganelli JD, et al. A metalloporphyrin-based superoxide dismutase mimic inhibits adoptive transfer of autoimmune diabetes by a diabetogenic T-cell clone. Diabetes. 2002;51(2):347-355.

13. Hussain SA. Silymarin as an adjunct to glibenclamide therapy improves long-term and postprandial glycemic control and body mass index in type 2 diabetes. J Med Food. 2007;10(3):543-547.

14. D'Aleo V, et al. The non-peptidyl low molecular weight radical scavenger IAC protects human pancreatic islets from lipotoxicity. Mol Cell Endocrinol. 2009;309(1-2):63-66.

15. Haldorsen IS, Raeder H, Vesterhus M, Molven A, Njolstad PR. The role of pancreatic imaging in monogenic diabetes mellitus. Nat Rev Endocrinol.
2011;8(3):148-159.

16. Pan FC, Wright C. Pancreas organogenesis: from bud to plexus to gland. Dev Dyn. 2011;240(3):530-565.

17. Zhang C, et al. MafA is a key regulator of glucose-stimulated insulin secretion. Mol Cell Biol. 2005;25(12):4969-4976

18. Artner I, et al. MafA and MafB regulate genes critical to beta-cells in a unique temporal manner. Diabetes. 2010;59(10):2530-2539.

19. Li J, Bergmann A, Reimann M, Schulze J, Bornstein SR, Schwarz PE. Genetic variation of Neurogenin 3 is slightly associated with hyperproinsulinaemia and progression toward type 2 diabetes. Exp Clin Endocrinol Diabetes. 2008;116(3):178-183.

20. Yasuda T, et al. PAX6 mutation as a genetic factor common to aniridia and glucose intolerance. Diabetes. 2002;51(1):224-230.

21. Ashery-Padan R, et al. Conditional inactivation of Pax6 in the pancreas causes early onset of diabetes. Dev Biol. 2004;269(2):479-488.

22. Robertson RP. Chronic oxidative stress as a central mechanism for glucose toxicity in pancreatic islet beta cells in diabetes. J Biol Chem. 2004; 279(41):42351-42354.

23. Harmon JS, Stein R, Robertson RP. Oxidative stress-mediated, post-translational loss of MafA protein as a contributing mechanism to loss of insulin gene expression in glucotoxic beta cells. J Biol Chem. 2005;280(12):11107-11113.

24. Ahlgren U, Jonsson J, Jonsson L, Simu K, Edlund $\mathrm{H}$. beta-cell-specific inactivation of the mouse Ipf1/ 
Pdx1 gene results in loss of the beta-cell phenotype and maturity onset diabetes. Genes Dev. 1998 ; 12(12):1763-1768.

25. Gannon M, Gamer LW, Wright CV. Regulatory regions driving developmental and tissue-specific expression of the essential pancreatic gene $\mathrm{pdx} 1$. Dev Biol. 2001;238(1):185-201.

26. Fujitani Y, et al. Targeted deletion of a cis-regulatory region reveals differential gene dosage requirements for $\mathrm{Pdx} 1$ in foregut organ differentiation and pancreas formation. Genes Dev. 2006; 20(2):253-266.

27. Park JH, Stoffers DA, Nicholls RD, Simmons RA. Development of type 2 diabetes following intrauterine growth retardation in rats is associated with progressive epigenetic silencing of Pdx1. J Clin Invest. 2008;118(6):2316-2324.

28. Poitout V, Hagman D, Stein R, Artner I, Robertson RP, Harmon JS. Regulation of the insulin gene by glucose and fatty acids. J Nutr. 2006;136(4):873-876.

29. Henseleit KD, Nelson SB, Kuhlbrodt K, Hennings JC, Ericson J, Sander M. NKX6 transcription factor activity is required for alpha- and beta-cell development in the pancreas. Development. 2005; 132(13):3139-3149.

30. Schisler JC, et al. The Nkx6.1 homeodomain transcription factor suppresses glucagon expression and regulates glucose-stimulated insulin secretion in islet beta cells. Proc Natl Acad Sci U S A. 2005; 102(20):7297-7302.

31. Stephens SB, et al. A VGF-derived peptide attenuates development of type 2 diabetes via enhancement of islet beta-cell survival and function. Cell Metab. 2012;16(1):33-43.

32. Benkhelifa S, Provot S, Nabais E, Eychene A, Calothy G, Felder-Schmittbuhl MP. Phosphorylation of MafA is essential for its transcriptional and biological properties. Mol Cell Biol. 2001;21(14):4441-4452.

33. Rocques N, et al. GSK-3-mediated phosphorylation enhances Maf-transforming activity. Mol Cell. 2007;28(4):584-597.

34. Guo S, et al. The stability and transactivation potential of the mammalian MafA transcription factor are regulated by serine 65 phosphorylation. J Biol Chem. 2009;284(2):759-765.

35. Guo S, Vanderford NL, Stein R. Phosphorylation within the MafA $\mathrm{N}$ terminus regulates $\mathrm{C}$-terminal dimerization and DNA binding. J Biol Chem. 2010;285(17):12655-12661.

36. Swingle M, Ni L, Honkanen RE. Small-molecule inhibitors of ser/thr protein phosphatases: specificity, use and common forms of abuse. Methods Mol Biol. 2007;365:23-38.

37. Elrick LJ, Docherty K. Phosphorylation-dependent nucleocytoplasmic shuttling of pancreatic duodenal homeobox-1. Diabetes. 2001;50(10):2244-2252.

38. Nishimura W, et al. A switch from MafB to MafA expression accompanies differentiation to pancreatic beta-cells. Dev Biol. 2006;293(2):526-539.

39. Artner I, et al. MafB is required for islet beta cell maturation. Proc Natl Acad Sci U S A. 2007; 104(10):3853-3858.

40. Chang CJ, Mulholland DJ, Valamehr B, Mosessian S, Sellers WR, Wu H. PTEN nuclear localization is regulated by oxidative stress and mediates p53-dependent tumor suppression. Mol Cell Biol. 2008;28(10):3281-3289.

41. Kitamura YI, et al. FoxO1 protects against pancreatic beta cell failure through NeuroD and MafA induction. Cell Metab. 2005;2(3):153-163.

42. Yan L, et al. The B55alpha-containing PP2A holoenzyme dephosphorylates FOXO1 in islet beta cells under oxidative stress. Biochem J. 2012;444(2):239-247.

43. Bonny C, Roduit R, Gremlich S, Nicod P, Thorens $\mathrm{B}$, Waeber G. The loss of GLUT2 expression in the pancreatic beta-cells of diabetic $\mathrm{db} / \mathrm{db}$ mice is associated with an impaired DNA-binding activity of islet-specific trans-acting factors. Mol Cell Endocrinol. 1997;135(1):59-65.

44. Matsuoka TA, et al. Regulation of MafA expression in pancreatic beta-cells in $\mathrm{db} / \mathrm{db}$ mice with diabetes. Diabetes. 2010;59(7):1709-1720.

45. Tartaglia LA, et al. Identification and expression cloning of a leptin receptor, OB-R. Cell. 1995; 83(7):1263-1271.

46. Chen $\mathrm{H}$, et al. Evidence that the diabetes gene encodes the leptin receptor: identification of a mutation in the leptin receptor gene in $\mathrm{db} / \mathrm{db}$ mice. Cell. 1996;84(3):491-495.

47. Talchai C, Xuan S, Lin HV, Sussel L, Accili D. Pancreatic $\beta$ cell dedifferentiation as a mechanism of diabetic $\beta$ cell failure. Cell. 2012;150(6):1223-1234

48. Parsons JA, Brelje TC, Sorenson RL. Adaptation of islets of Langerhans to pregnancy: increased islet cell proliferation and insulin secretion correlates with the onset of placental lactogen secretion. Endocrinology. 1992;130(3):1459-1466.

49. Weir GC, Bonner-Weir S. Five stages of evolving $\beta$-cell dysfunction during progression to diabetes. Diabetes. 2004;53(suppl 3):S16-S21.

50. Rhodes CJ. Type 2 diabetes-a matter of $\beta$-cell life and death? Science. 2005;307(5708):380-384.

51. Sachdeva MM, Stoffers DA. Minireview: Meeting the demand for insulin: molecular mechanisms of adaptive postnatal $\beta$-cell mass expansion. Mol Endocrinol. 2009;23(6):747-758.

52. Dorrell C, et al. Transcriptomes of the major human pancreatic cell types. Diabetologia. 2011; 54(11):2832-2844.

53. Dai C, et al. Islet-enriched gene expression and glucose-induced insulin secretion in human and mouse islets. Diabetologia. 2012;55(3):707-718.

54. Artner I, et al. MafB: an activator of the glucagon gene expressed in developing islet alpha- and betacells. Diabetes. 2006;55(2):297-304.

55. Evans JL, Goldfine ID, Maddux BA, Grodsky GM. Oxidative stress and stress-activated signaling pathways: a unifying hypothesis of type 2 diabetes. Endocr Rev. 2002;23(5):599-622.

56. Poli G, Leonarduzzi G, Biasi F, Chiarpotto E. Oxidative stress and cell signalling. Curr Med Chem. 2004; 11(9):1163-1182.

57. Khanday FA, et al. Rac1 leads to phosphorylation-dependent increase in stability of the p66shc adaptor protein: role in Rac1-induced oxidative stress. Mol Biol Cell. 2006;17(1):122-129.

58. Kondo T, et al. p38 MAPK is a major regulator of MafA protein stability under oxidative stress. $\mathrm{Mol}$ Endocrinol. 2009;23(8):1281-1290.

59. Rebolledo OR, Actis Dato SM. Postprandial hyperglycemia and hyperlipidemia-generated glycoxidative stress: its contribution to the pathogenesis of diabetes complications. Eur Rev Med Pharmacol Sci. 2005;9(4):191-208.

60. Shiraiwa T, et al. Postprandial hyperglycemia is a better predictor of the progression of diabetic retinopathy than HbA1c in Japanese type 2 diabetic patients. Diabetes Care. 2005;28(11):2806-2807.
61. Malecki MT. Genetics of type 2 diabetes mellitus. Diabetes Res Clin Pract. 2005;68(suppl 1):S10-S21.

62. D'Alessio D. The role of dysregulated glucagon secretion in type 2 diabetes. Diabetes Obes Metab. 2011;13(suppl 1):126-132.

63. Shao C, Cobb MH. Sumoylation regulates the transcriptional activity of MafA in pancreatic beta cells. J Biol Chem. 2009;284(5):3117-3124.

64. Ihara $Y$, et al. Hyperglycemia causes oxidative stress in pancreatic $\beta$-cells of GK rats, a model of type 2 diabetes. Diabetes. 1999;48(4):927-932.

65. Ferrannini E. The stunned beta cell: a brief history. Cell Metab. 2010;11(5):349-352.

66. Rabiee A, et al. Hyperinsulinemic hypoglycemia after Roux-en-Y gastric bypass: unraveling the role of gut hormonal and pancreatic endocrine dysfunction. J Surg Res. 2011;167(2):199-205.

67. Salehi M, Prigeon RL, D’Alessio DA. Gastric bypass surgery enhances glucagon-like peptide 1-stimulated postprandial insulin secretion in humans. Diabetes. 2011;60(9):2308-2314.

68. D'Amour KA, et al. Production of pancreatic hormone-expressing endocrine cells from human embryonic stem cells. Nat Biotechnol. 2006; 24(11):1392-1401.

69. Kroon E, et al. Pancreatic endoderm derived from human embryonic stem cells generates glucose-responsive insulin-secreting cells in vivo. Nat Biotechnol. 2008;26(4):443-452.

70. Schaffer AE, et al. Nkx6.1 controls a gene regulatory network required for establishing and maintaining pancreatic $\beta$-cell identity. PLoS Genet. 2013; 9(1):e1003274.

71. Hosokawa K, Yamaguchi H, Ikehara T, Takahashi A, Miyamoto H. Stimulating effects of insulin and low-density lipoprotein on cell growth and macromolecular syntheses of HeLa cells cultured in $\mathrm{K}(+)$-depleted medium. J Cell Physiol. 1990;144(2):254-261.

72. Hamaguchi K, Leiter EH. Comparison of cytokine effects on mouse pancreatic alpha-cell and beta-cell lines. Viability, secretory function, and MHC antigen expression. Diabetes. 1990;39(4):415-425.

73. Ohno T, et al. Genistein augments cyclic adenosine 3'5'-monophosphate(cAMP) accumulation and insulin release in MIN6 cells. Endocr Res. 1993; 19(4):273-285.

74. Efrat $\mathrm{S}$, et al. Beta-cell lines derived from transgenic mice expressing a hybrid insulin gene-oncogene. Proc Natl Acad Sci U S A. 1988;85(23):9037-9041.

75. Raum JC, et al. FoxA2, Nkx2.2, and PDX-1 regulate islet beta-cell-specific mafA expression through conserved sequences located between base pairs -8118 and -7750 upstream from the transcription start site. Mol Cell Biol. 2006;26(15):5735-5743.

76. Zhao L, Cissell MA, Henderson E, Colbran R, Stein $\mathrm{R}$. The RIPE3b1 activator of the insulin gene is composed of a protein(s) of approximately 43 $\mathrm{kDa}$, whose DNA binding activity is inhibited by protein phosphatase treatment. J Biol Chem. 2000; 275(14):10532-10537.

77. Brissova M, et al. Reduction in pancreatic transcription factor PDX-1 impairs glucose-stimulated insulin secretion. J Biol Chem. 2002;277(13):11225-11232.

78. Bustin SA, et al. The MIQE guidelines: minimum information for publication of quantitative real-time PCR experiments. Clin Chem. 2009;55(4):611-622.

79. Matsuoka TA, et al. Members of the large Maf transcription family regulate insulin gene transcription in islet beta cells. Mol Cell Biol. 2003;23(17):6049-6062. 